\title{
Naturaleza vulnerada. Cuatro décadas de AGRICULTURA INDUSTRIALIZADA DE FRUTAS Y HORTALIZAS EN EL SUR DE JALISCO, MÉXICO (1980-2020)
}

\author{
Vulnered Nature. Four Decades of Industrialized \\ Agriculture of Fruits and Vegetables in the South of \\ JALISCO, MeXico (1980-2020)
}

\author{
Alejandro Macías Macías* \\ Yolanda Lizeth Sevilla García** \\ DOI: https://doi.org/10.31644/ED.V8.N1.2021.A03
}

Resumen: La producción industrializada de hortalizas y frutas en el sur de Jalisco, México ha tenido un crecimiento espectacular durante las más recientes cuatro décadas. Sin embargo, su desarrollo está basado en buena medida en la sobreexplotación del medio ambiente, situación que incluso puede llegar a poner en riesgo la viabilidad futura de la vida humana, así como de otras especies. A la luz del concepto "naturaleza vulnerada", en este trabajo se discuten dichos impactos en aspectos clave como los cambios de uso de suelo y la menor extensión de los bosques, así como la disminución de las reservas de agua, impactos derivados principalmente del crecimiento en las plantaciones de aguacate a partir del ańo 2000.

Palabras clave: naturaleza vulnerada, producción hortofrutícola, sur de Jalisco, bosques, agua.

Abstract: The industrialized production of vegetables and fruits in the South of Jalisco, Mexico has had a spectacular growth in the last four decades. However, its development is largely based on the overexploitation of the environment, a situation that can put at risk the future viability of human life, as well as that of other species. Using the concept of vulnerable nature, this work discusses such impacts in key aspects such as changes in land use and the reduced extension of forests, as well as the decrease in water reserves. These impacts are derived mainly from the growth in avocado plantations since 2000.

Keywords: vulnerable nature, fruit and vegetable production, southern Jalisco, forests, water.

* Dr. en Ciencias Sociales, profesor investigador del Centro Universitario del Sur, Universidad de Guadalajara, México. ORCiD: https://orcid.org/0000-0002-1359-3402 Correo-e: alejandrom@cusur.udg.mx; amacias40@ hotmail.com.

** Maestra en Ciencias del Comportamiento, profesora investigadora del Centro Universitario del Sur, Universidad de Guadalajara, México. ORCiD: https://orcid.org/0000-0001-5752-7194_Correo-e: lizeth.sevilla@cusur.udg.mx. Fecha de recepción: 19/06/2020. Fecha de aceptación: 29/10/2020. Fecha de publicación: 30/01/2021.

\section{(cc) BY-NC-ND}

EntreDiversidades. Revista de Ciencias Sociales y Humanidades, vol. 8, núm. 1 (16), enero-junio 2021. Páginas: 64 - 91 ISSN-e: 2007-7610. https://doi.org/10.31644/ED.V8.N1.2021.A03 


\section{Introducción}

La crisis macroeconómica de 1982, la globalización de los mercados y la irrupción del neoliberalismo en México modificaron drásticamente los equilibrios productivos en las zonas rurales de la nación, iniciando con las regiones más fértiles. Una de ellas fue el sur del estado de Jalisco, en el occidente de México, cuya estructura agrícola —-dedicada tradicionalmente en buena medida a la producción de granos y forrajes por parte de empresarios locales - pronto comenzó a ser transformada por la irrupción de agroempresarios vinculados con la producción de "mercancías alimenticias" (McMichael, 1994), debido a las ventajas comparativas que presenta la región. Primero por las hortalizas y después por las frutas, el sur jalisciense se ha convertido en una potencia agrícola con productos que son exportados a diversas partes del mundo.

Sin embargo, la nueva cara que presenta el campo de esta región no es la que en un principio imaginaban sus habitantes. Si bien existe un importante dinamismo económico, también se han generado severos dańos a la naturaleza, los cuales tienden a profundizarse con el tiempo. En su fase más intensa, a partir del inicio del siglo XXI, la rápida expansión de las plantaciones de aguacates y berries han modificado drásticamente el paisaje rural, acabando con importantes áreas boscosas; los daños que ello ha ocasionado a los mantos freáticos, a la flora y a la fauna local son preocupantes.

El presente trabajo consta de tres partes. En la primera, se analiza teóricamente la perversa relación que invariablemente existe entre agricultura industrializada y medio ambiente, lo que deriva en el concepto de "naturaleza vulnerada". En la segunda, se hace un recorrido cronológico respecto al surgimiento y evolución de la producción industrializada de frutas y hortalizas en el sur de Jalisco, mientras que la tercera parte presenta a grandes rasgos los impactos ambientales ocasionados por las agroempresas que trabajaron en la región, principalmente en la década de 1990, y, con mayor detalle, los impactos derivados de la actividad frutícola en lo que va del siglo XXI. Finalmente, se presentan las conclusiones.

\section{Agricultura industrializada y naturaleza vulnerada}

A nivel mundial, el modelo agroindustrial hegemónico, que Philip McMichael (2002) llama régimen alimentario corporativo (corporate food regime), se caracteriza por imponer una agricultura global orientada por los intereses mercantilistas de grandes consorcios agroindustriales, principalmente proveedores de insumos e intermediarios minoristas. En este, la función principal no es tanto la producción de alimentos, sino la generación de materias primas que permitan elaborar "mercancías alimentarias" (McMichael, 1994), de manera que los agronegocios buscan maximizar sus respectivas funciones de utilidad mercantil a través de la incorporación de principios importados de la economía industrial, tales como uniformidad, racionalidad, especialización e intensificación de los procesos productivos.

Al ser la búsqueda de utilidades el elemento central que mueve las decisiones en este régimen agroindustrial, las empresas ejercen diversas acciones para conseguirlas. En este sentido, los intermediarios minoristas, que aglutinan un creciente poder, buscan competir a través de políticas basadas en precios bajos y altos estándares de calidad. Ello lo logran mediante una mayor coordinación vertical y control sobre sus proveedores (De Schutter, 2009: 5), a los cuales les exige

EntreDiversidades. Revista de Ciencias Sociales y Humanidades, vol. 8, núm. 1 (16), enero-junio 2021. Páginas: 64 - 91 ISSN-e: 2007-7610. https://doi.org/10.31644/ED.V8.N1.2021.A03 
castigar sus costos de producción sin que ello perjudique la calidad de los alimentos; incluso demandan la provisión de elevados volúmenes de oferta que disminuyen los costos unitarios, así como el cumplimiento de estrictas normas sanitarias y de diversidad de oferta, sin perder la homogeneidad del producto; es decir, exigen se les manden constantemente diferentes productos de distintas variedades, pero cada una debe ser homogénea en términos de tamaño, color, etc.

Tales exigencias son trasladadas a lo largo de la cadena mercantil hasta la fase de producción primaria, donde las agroempresas se ven obligadas a realizar una serie de maniobras para poder mantenerse en el mercado. Entre ellas, se encuentra la de administrar sus unidades de producción con métodos industriales, dejando en segundo término el cuidado de los recursos territoriales, de los seres vivos sobre los que obtienen los productos, de los trabajadores y hasta de los propios consumidores. Es decir, si el objetivo es maximizar la utilidad, sujeta a grandes restricciones de los compradores, entonces las empresas se enfocan en ello sin incorporar en sus funciones de producción las elevadas externalidades negativas que esto genera.

Entre las cadenas agroproductoras que bajo este esquema más han crecido en las décadas recientes se encuentran las frutas y las hortalizas ${ }^{1}$, considerados cultivos comerciales altamente especulativos en la medida en que ofrecen elevadas utilidades por hectárea sembrada, aun cuando también requieren grandes inversiones y están expuestos a importantes riesgos de tipo medioambiental y de comercio. En este tipo de cadenas las agroempresas ejecutan diversas estrategias para acceder a las utilidades, a la vez que aminoran los costos y riesgos. Una de ellas consiste en aprovechar la disminución de las barreras a la movilidad del capital para incrementar la dispersión geográfica de sus unidades de producción, tanto para aprovechar las ventajas comparativas de los distintos territorios como para tener una oferta constante. Tal situación origina una creciente desvinculación geográfica de la producción agrícola respecto del consumo y una intensificación del comercio internacional ${ }^{2}$, además de motivar el desarrollo de zonas productivas en países que poseen ventajas medioambientales, mano de obra barata y una rica diversidad biológica, así como leyes laxas para producir a bajo costo.

En las nuevas zonas de producción las agroempresas utilizan distintos mecanismos para acceder a los recursos estratégicos y disminuir los riesgos asociados con su uso. Estos mecanismos son aplicados diferenciadamente dependiendo del producto y sus características, así como del destino que este tenga, aunque siempre se utiliza el medio ambiente y sus recursos con una perspectiva individualista, que maximice las utilidades en el corto plazo, sin que realmente se atienda el cuidado de la naturaleza. En ese marco, las agroempresas y los agricultores vinculados a ellas realizan acciones como hacer cambios de uso de suelo sin considerar las consecuencias que ello tiene sobre los ecosistemas que existen en los territorios; implementan sistemas de producción intensiva para disminuir los costos por unidad, utilizando en ocasiones los recursos territoriales — suelo, agua y recursos bióticos_ a tasas mucho mayores que las consideradas sustentables;

\footnotetext{
${ }^{1}$ A nivel mundial, entre 1970 y 2018 la superficie sembrada con frutas creció un 1.64\% promedio anual, mientras que las hortalizas lo hicieron el $2.20 \%$, los cítricos un $2.71 \%$ y las frutas secas el $3.39 \%$ promedio anual. Esto contrasta, por ejemplo, con el crecimiento en la superficie sembrada de cereales, que fue de $0.16 \%$ (FAO-Faostat, 2020).

${ }^{2}$ Las exportaciones mundiales de frutas y hortalizas tuvieron una tasa de crecimiento promedio anual (TCA) de 8.14\% entre 1970 y 2017, de manera que en 2017 representaron el 18.3\% de todas las exportaciones agropecuarias, cuando en 1961 el porcentaje era de 10.5\% (FAO-Faostat, 2020).
}

EntreDiversidades. Revista de Ciencias Sociales y Humanidades, vol. 8, núm. 1 (16), enero-junio 2021. Páginas: 64 - 91 ISSN-e: 2007-7610. https://doi.org/10.31644/ED.V8.N1.2021.A03 
aplican en demasía toda clase de productos sintéticos — fertilizantes, agrotóxicos y plásticos—, con la única limitación en sus funciones de producción y en las restricciones impuestas por los países compradores; generan contaminación sin aplicar las medidas de seguridad estipuladas por las leyes nacionales y locales, etc. Las consecuencias de tales decisiones es un medio ambiente que comienza a ser inhóspito, tanto para el ser humano como para otras especies animales y vegetales, por lo que estos se vuelven más vulnerables ante fenómenos futuros.

El concepto de "vulnerabilidad", originalmente utilizado en la geografía y en las ciencias ambientales, tiene cada vez más connotaciones conforme es empleado por otras ciencias (Alwang, et al., 2001; Hufschmidt, 2011). No obstante, en términos generales, puede definirse como las condiciones de fragilidad que presenta un ecosistema o algunos de sus componentes para protegerse de un daño ocasionado por alguna fuerza o energía potencialmente destructiva, o la incapacidad del mismo para reponerse de sus efectos (GTZ, ONU y CEPAL, 2005: 9). La vulnerabilidad se incrementa o disminuye de acuerdo a los niveles de exposición (grado al que se entra en contacto con un riesgo particular), sensibilidad (niveles en que puede ser afectado por la exposición) y resiliencia (capacidad para resistir o recuperarse del dańo ocasionado por diversas presiones) que los ecosistemas o los grupos humanos presentan en determinadas circunstancias (Smit y Pilifosova, 2003).

Con base en lo anterior, las afectaciones ocasionadas por el ser humano al medio ambiente y las consecuencias que ello trae consigo remiten al concepto de "naturaleza vulnerada", el cual entendemos en este trabajo como la condición de deterioro que sufre un entorno medioambiental debido a la acción humana, lo que incrementa los niveles de exposición y sensibilidad de los seres que viven en él ante potenciales riesgos futuros, disminuyendo sus condiciones de vida en ese entorno y sus capacidades de respuesta ante tales fenómenos.

En México la naturaleza ha sido vulnerada por la agricultura industrializada de frutas y hortalizas en diversas regiones y en distintas épocas, generando agotamiento de recursos, contaminación, incremento de enfermedades, proliferación de plagas agrícolas, así como otros daños que incluso han derivado en el enfrentamiento entre la sociedad y las agroempresas, y, en muchos casos, en la terminación de la propia actividad productiva, con consecuencias económicas negativas para los territorios y sus habitantes. Esto ha sido ampliamente documentado en distintas regiones del país, como el valle de San Quintín en Baja California (Cook y Amon, 1989), el valle de Arista en San Luis Potosí (Maisterrena y Mora, 2000), Hermosillo en Sonora (Moreno, 2000), el valle de Apatzingán en Michoacán (Stanford, 1994), los valles de tierra caliente de Guerrero (Bustamante y Etienne, 1999), el valle de Zamora en Michoacán (Sefó, 2005), el valle de Autlán en Jalisco (González, 1994), el valle de Sayula en Jalisco (Macías, 2008) y la zona aguacatera de Michoacán (Barsimantov y Navia, 2012), entre otros.

En las siguientes líneas haremos lo propio con lo sucedido en el medio ambiente del sur de Jalisco desde la llegada de las empresas hortícolas en 1986, pero principalmente a raíz del desarrollo de las plantaciones frutícolas a partir del año 2000. Para ello, se hará una crónica del proceso de desarrollo de estas actividades agrícolas y de los impactos ambientales por ellas generados, a partir de información obtenida en otras investigaciones realizadas por los autores, así como a través de otras fuentes estadísticas, hemerográficas y bibliográficas.

EntreDiversidades. Revista de Ciencias Sociales y Humanidades, vol. 8, núm. 1 (16), enero-junio 2021. Páginas: 64 - 91 ISSN-e: 2007-7610. https://doi.org/10.31644/ED.V8.N1.2021.A03 


\section{Crisis macroeconómica, neoliberalismo e irrupción de nuevas agroempresas en el campo del sur de Jalisco}

En este trabajo entendemos como sur de Jalisco al área de 27 municipios localizada al suroeste del lago de Chapala y al noreste del volcán de Colima ${ }^{3}$. Al ser atravesado por dos grandes sierras, dicho territorio es rico en recursos naturales, situación que le ha permitido tener, desde la época de la colonia, una agricultura próspera.

Desde el término de la Revolución mexicana, pero particularmente a partir de la "revolución verde" iniciada en los años cuarenta del siglo XX, la agricultura regional vivió un rápido proceso evolutivo hacia su creciente mecanización, irrigación, uso de semillas mejoradas, fertilizantes inorgánicos y agroquímicos, así como una mayor vinculación con los mercados regionales, después nacionales y, en las más recientes décadas, internacionales. Surgieron diversos agroempresarios locales y algunos foráneos, así como grupos ejidales que aprovecharon la fertilidad de los suelos para adquirir poder económico y social en los distintos municipios (De la Peńa, 1999: 42) mediante el cultivo de maíz, cańa de azúcar y forrajes, entre otros, los cuales se vendían en distintos mercados del país o se destinaban a la agroindustria.

Sin embargo, en 1982 México cayó en una profunda crisis macroeconómica que llevó al país a terminar con el modelo de sustitución de importaciones y a abrazar el neoliberalismo. Este cambio supuso modificaciones estructurales en la política agrícola del país, debido a la drástica reducción de los apoyos gubernamentales al campo, el cierre o venta de empresas paraestatales, la apertura de varios sectores a la inversión privada que hasta entonces habían permanecido restringidos a ella y, en general, la liberalización del comercio, así como las modificaciones realizadas en 1992 al artículo 27 de la Constitución, que dieron la posibilidad al capital privado de acceder a tierras ejidales.

Las nuevas condiciones provocaron en la agricultura del sur jalisciense una creciente irrupción de nuevos actores, productos y formas de producción. Mientras buena parte de los productores locales caían en crisis por la falta de rentabilidad de sus cultivos — principalmente maíz y forrajes como alfalfa o sorgo - debido a la apertura comercial, la importación de productos sustitutos y la propia crisis de la producción pecuaria regional, otros actores externos a la región encontraban la oportunidad de incursionar en este territorio a través de la producción de cultivos intensivos que, en el nuevo discurso neoliberal, presentaban "ventajas comparativas".

Un primer esfuerzo en este sentido se dio durante la década de 1970, cuando iniciaron las pruebas para producir papa en la sierra de Tapalpa, cuya superficie alcanzó 350 hectáreas en el quinquenio 1976-1980 (Sánchez Bacilio, 1992: 3). Más adelante, entre 1985 y 1986, a la vez que incursionaban empresas nacionales y trasnacionales para reproducir nuevas variedades de semillas híbridas de maíz — que posteriormente se comercializaban en el territorio nacional—, emergió también la producción industrializada de jitomate y chile en el valle de Sayula (Macías, 2011).

\footnotetext{
${ }^{3}$ Estos municipios son: Amacueca, Atemajac de Brizuela, Atoyac, Chiquilistlán, Concepción de Buenos Aires, Gómez Farías, Jilotlán de los Dolores, La Manzanilla de la Paz, Mazamitla, Pihuamo, Quitupan, San Gabriel, Santa María del Oro, Sayula, Tamazula de Gordiano, Tapalpa, Tecalitlán, Techaluta de Montenegro, Teocuitatlán de Corona, Tolimán, Tonila, Tuxpan, Valle de Juárez, Zacoalco de Torres, Zapotilitic, Zapotitlán de Vadillo y Zapotlán el Grande.

EntreDiversidades. Revista de Ciencias Sociales y Humanidades, vol. 8, núm. 1 (16), enero-junio 2021. Páginas: 64 - 91 ISSN-e: 2007-7610. https://doi.org/10.31644/ED.V8.N1.2021.A03
} 
Para la década siguiente, las siembras de estas hortalizas de alto valor agregado poco a poco fueron creciendo en ambas subregiones, de forma que para el año 2000 sumaban 1417 hectáreas de jitomate y 2440 hectáreas de papa. Aunque esta superficie apenas representaba el $1.74 \%$ del total agrícola en el sur jalisciense, su contribución al valor económico regional generado por la agricultura fue en ese año del $24.6 \%$, gracias a 302 millones de pesos derivados de la producción de jitomate y 252 millones de pesos por el cultivo de papa.

La siembra de jitomate en el valle de Sayula fue realizada principalmente por agroempresas foráneas - mayoritariamente originarias de Sinaloa- (Gráfica 1), que rentaron las tierras más productivas del valle, anteriormente destinadas a la siembra de alfalfa ${ }^{4}$. Solo algunos pocos agricultores locales, medianamente capitalizados y con cierta experiencia en la producción de hortalizas por haber laborado para las agroempresas, incursionaron en la producción de jitomate, generalmente sembrando pequeñas superficies — no más de 20 hectáreas - y destinando la producción para los mercados regionales (Macías, 2011). Por su parte, la mayoría de la producción de papa en Tapalpa fue destinada a agroindustrias trasnacionales, entre ellas el consorcio PepsiCo.

\section{Gráfica 1. Superficie sembrada de jitomate (hectáreas) por principales empresas en el valle de Sayula, Jalisco (1999)}

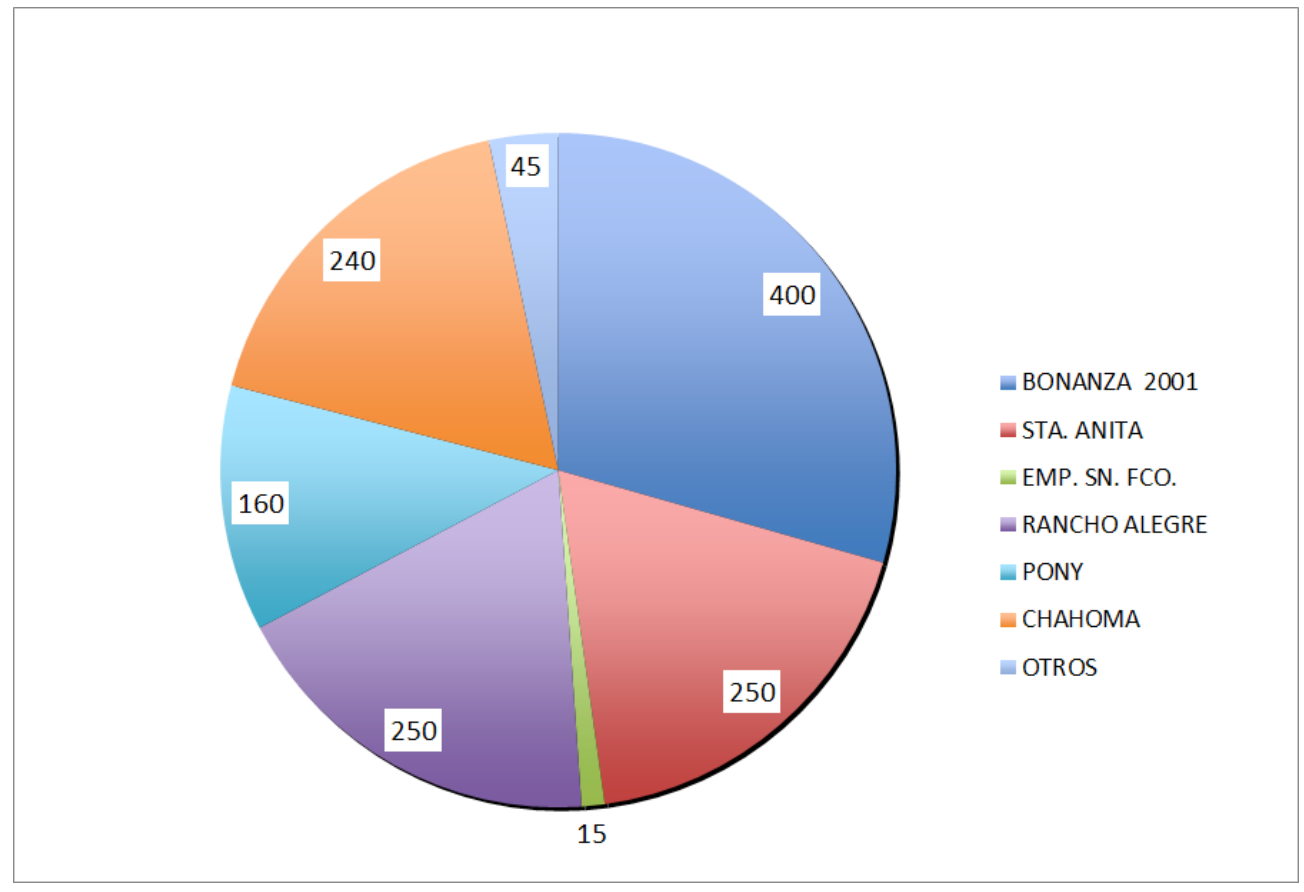

Fuente: Elaborado con base en información proporcionada por Oficina de Sayula de la Secretaría de Agricultura, Ganadería y Desarrollo Rural (SAGAR).

\footnotetext{
${ }^{4}$ Este cultivo había sido el más rentable de Sayula durante los ańos setenta, antes de la apertura comercial y el incremento en la importación de alimentos sustitutos para el ganado.
}

EntreDiversidades. Revista de Ciencias Sociales y Humanidades, vol. 8, núm. 1 (16), enero-junio 2021. Páginas: 64 - 91 ISSN-e: 2007-7610. https://doi.org/10.31644/ED.V8.N1.2021.A03 
Otra nueva actividad hortícola inició en 1994 en el valle de Sayula, cuando algunos de los antiguos productores locales de alfalfa buscaron salir de la crisis en la que se encontraban mediante el establecimiento de contratos con empresas originarias de los estados de Guanajuato y Aguascalientes — particularmente de la empresa Frigoríficos La Huerta-, dedicadas desde los ańos setenta a la producción y venta de hortalizas congeladas. Tales contratos se crearon con el fin de producir y abastecer a dichas empresas en la temporada de invierno con productos como brócoli, cebolla, maíz dulce, chícharo, ejote, espinaca, perejil, zanahoria, betabel, pimiento, etc. (Macías, 2011: 340). En el caso del brócoli, que fue la hortaliza con mayor producción, la superficie máxima se alcanzó en 2013, cuando llegaron a sembrarse 1590 hectáreas en el sur jalisciense, la mayoría de ellas en el valle de Sayula (SADER-SIAP, 2020).

La agricultura industrializada de hortalizas en la región comenzó a decaer en los años siguientes, principalmente por los impactos ambientales que las empresas habían generado, así como por las presiones sociales debido a las condiciones de vida y trabajo que proporcionaban a sus jornaleros migrantes $^{5}$. En el caso del jitomate y el chile, una crisis de plagas ocurrida durante los años 2003 y 2004 prácticamente acabó con su producción a cielo abierto (Macías, 2011), manteniéndose solo el cultivo de jitomate bajo invernadero, que en 2005 sumaron 128 hectáreas, por 470.5 hectáreas en 2018 (SADER-SIAP, 2020). Por su parte, la producción de brócoli disminuyó porque comenzaron a aparecer nuevas opciones de cultivos más rentables como las frutas, de manera que en 2018 se destinaron a esta hortaliza 454 hectáreas, $71.4 \%$ menos que en 2013. En cuanto a la producción de papa, la superficie sembrada disminuyó ligeramente a partir de 2005, aunque se ha mantenido en el rango de 1750 a 2200 hectáreas en la sierra de Tapalpa.

En general, durante 2018 fueron sembradas 15 tipos de hortalizas en el sur de Jalisco, aunque la mayoría cubriendo pequeñas extensiones, pues además de la papa solo otras dos hortalizas alcanzaron una superficie superior a las mil hectáreas: el tomate verde, con 1133 hectáreas - 1905 hectáreas en 2000- y el elote, producido bajo contrato con las mismas empresas mencionadas de precongelados, con 1965 hectáreas. Así, la horticultura en general pasó de aportar el 33.6\% del valor agrícola regional en el año 2000 a solo el 14.6\% en 2018 .

Mientras la horticultura perdía rentabilidad, comenzaba el despegue de la fruticultura industrializada, primeramente con la producción de aguacate. Aunque las huertas dedicadas a esta fruta existen en la región desde los años setenta del siglo XX, hasta 1999 no representaban un negocio, de manera que apenas existían 305.8 hectáreas plantadas, la mayoría instaladas en las partes bajas de la Sierra del Tigre, en los municipios de Zapotlán el Grande y Gómez Farías (Macías, 2010). Los dueños de estas huertas eran productores medianos dedicados a otras actividades, de manera que el aguacate no representaba su principal fuente de ingresos.

Es a partir del año 2000 cuando comienza el crecimiento constante en el número de huertas y en la superficie plantada con aguacate Hass por toda la región, alcanzando en 2019 un total de 20315 hectáreas registradas (Gráfica 2), distribuidas en 25 de los 27 municipios

${ }^{5}$ Dado que no es el objeto principal de este trabajo, no profundizaremos más sobre este tema, pero el lector o lectora puede consultar mayores detalles al respecto en Macías (2011).

EntreDiversidades. Revista de Ciencias Sociales y Humanidades, vol. 8, núm. 1 (16), enero-junio 2021. Páginas: 64 - 91 ISSN-e: 2007-7610. https://doi.org/10.31644/ED.V8.N1.2021.A03 


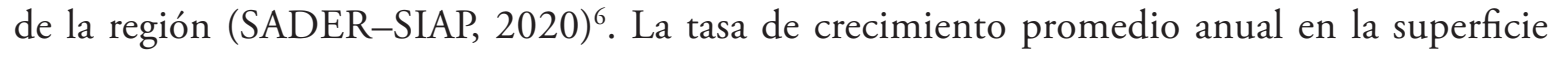
plantada con aguacate es de $23.3 \%$ entre 1999 y 2019, lo que significa que cada cuatro ańos se duplica esta superficie.

\section{Gráfica 2. Superficie plantada con aguacate en el sur de Jalisco (hectáreas)}

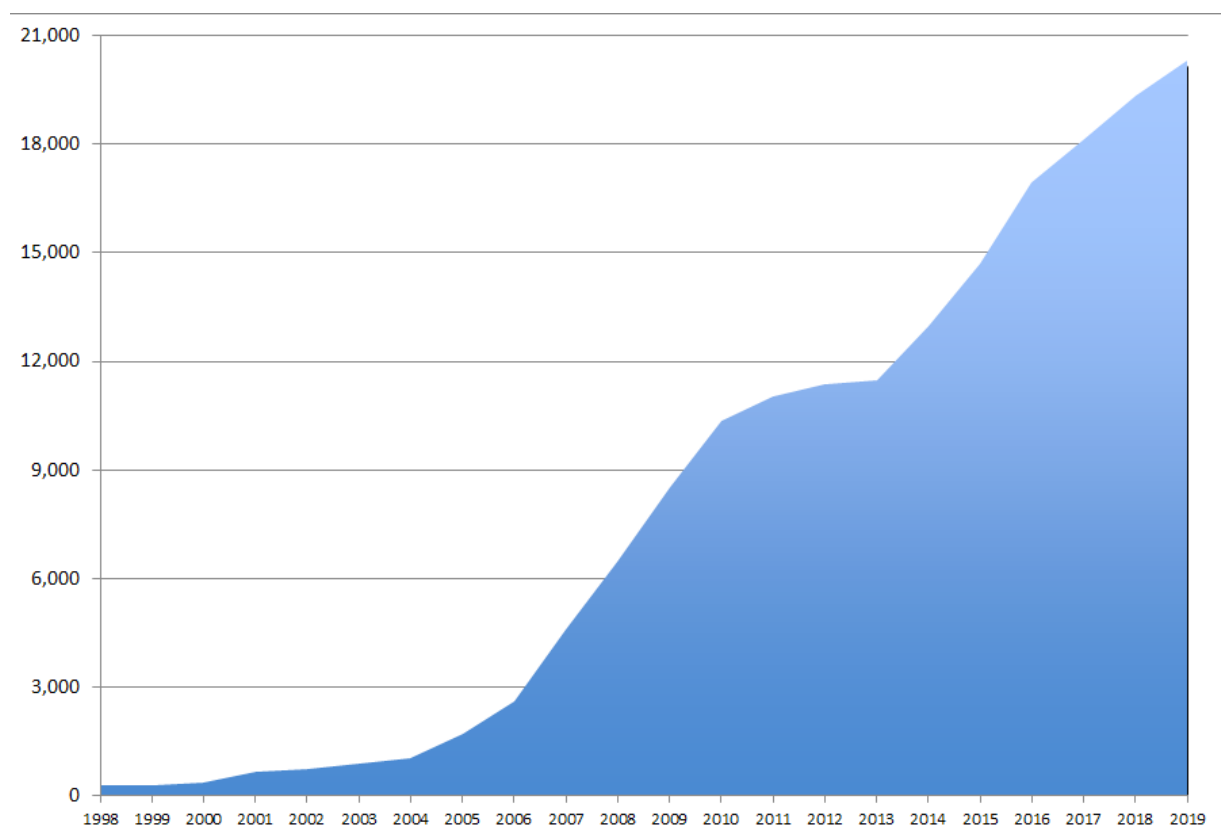

Fuente: Elaborado con base en SADER-SIAP. Anuarios estadísticos de producción agrícola.

Entre los factores que se combinaron para ocasionar el rápido crecimiento de la producción aguacatera en la región, se encuentra la apertura del mercado de los Estados Unidos de América a la importación de aguacate producido en México, que estuvo vedado entre 1914 y 1993 por razones fitosanitarias. Aunque hasta la fecha esta oportunidad solo existe para los agricultores de los municipios con mayor producción de aguacate de Michoacán, el incremento de la demanda externa e interna, derivada también de la identificación de efectos benéficos que esta fruta tiene para la salud humana y los productos diversificados que se pueden fabricar con su pulpa, motivó a los empacadores de aquel estado a buscar vías alternas de abastecimiento para cubrir la demanda nacional. Esto incentivó el establecimiento de huertas aguacateras en regiones emergentes con adecuadas condiciones agroecológicas; entre las principales se encuentran las diversas sierras del sur de Jalisco, al tener características similares a las de la zona aguacatera de Michoacán por ser parte del mismo macizo montañoso.

\footnotetext{
${ }^{6}$ Según el periodista Agustín del Castillo, en 2019 existían en realidad 28 mil 833.5 hectáreas en las regiones Sierra del Tigre y Complejo Volcánico de Colima, mientras que varios productores afirman que la superficie aguacatera en la región superó las 30 mil hectáreas. La razón de tales diferencias respecto de la información oficial es que algunas huertas no se registran sino hasta que empiezan a crecer los árboles, mientras otras no lo hacen por estar instaladas en terrenos con cambio clandestino en el uso de suelo.
}

EntreDiversidades. Revista de Ciencias Sociales y Humanidades, vol. 8, núm. 1 (16), enero-junio 2021. Páginas: 64 - 91 ISSN-e: 2007-7610. https://doi.org/10.31644/ED.V8.N1.2021.A03 
A nivel regional, otros dos hechos fueron también relevantes para el desarrollo de esta nueva actividad productiva. Uno fue el término de la concesión otorgada a la Compañía Industrial de Atenquique para la explotación exclusiva de 1 millón 46 mil 202 hectáreas de bosque en el sur de Jalisco durante 1995, lo que facilitó el desarrollo de nuevas actividades económicas en las zonas serranas. El otro consistió en la puesta en operación, a partir de 2008, de las presas El Carrizo y Vista Hermosa, en el municipio de Tamazula de Gordiano, las cuales tienen en conjunto una capacidad de almacenamiento de 89 millones de metros cúbicos $\left(\mathrm{Mm}^{3}\right)$ para incorporar 6494 hectáreas al riego tecnificado (CONAGUA, 2008; SEMARNAT-DGIRA, 2007). Aunque estas presas tenían como objetivo beneficiar a los productores de caña de azúcar, su construcción favoreció la instalación de varias huertas de aguacate donde antes había agricultura de temporal.

En los primeros años del auge aguacatero, entre 2000 y 2007, la mayor parte de los productores eran originarios del sur de Jalisco, muchos de los cuales tenían huertas pequeñas menores a cinco hectáreas (Macías y Sevilla, 2015: 108). Sin embargo, a partir de que en 2008 la entonces Secretaría de Agricultura, Ganadería, Desarrollo Rural, Pesca y Alimentación (SAGARPA) declaró a los municipios de Zapotlán el Grande y Gómez Farías como zonas libres de gusano barrenador del hueso — proceso previo para poder exportar a Estados Unidos_, la región se volvió atractiva para que agricultores y empresas foráneas comenzaran a llegar, instalando huertas mayores a 100 hectáreas, así como diversos empaques para la selección y clasificación de la fruta. A los dos empaques de capital local que iniciaron desde la primera década del siglo XXI —Agro Gonzámex y Avocados Deliseos- se han añadido otros nueve de capital nacional y trasnacional: Mevi Avocados, Calavo avocados, Avo Alze, Grupo Aguacatero Los Cerritos, Aguacates Los Volcanes, Freshjal, Roquin Empaque, Riveravo y Aguiva Avocados.

En 2006 inició una nueva cadena frutícola en el sur de Jalisco, cuando la empresa norteamericana Driscoll's decidió utilizar 61 hectáreas en Zapotlán el Grande para producir planta patentada de fresa, la cual después vendía a los agricultores con los que trabajaba en otras partes de México. Un año después, el gobierno de Jalisco y la Fundación Jalisco Produce impulsaron el "Programa de Desarrollo de la Industria de Berries en el estado de Jalisco", con el objeto de hacer del sur del estado una región altamente exportadora de arándano, frambuesa y otras berries mediante de contratos entre productores locales y empresas trasnacionales — norteamericanas y chilenas principalmente-. Dicho programa buscaba incluir en un lapso de cuatro años a 687 productores pequeños y 63 medianos al cultivo de berries, mediante distintos programas de apoyo por parte de los gobiernos estatal y federal.

Para la implementación del programa la Fundación Jalisco Produce estableció alianzas estratégicas con empresas líderes en tecnología y comercialización de berries a nivel internacional, con el objetivo de que fueran proveedoras de variedades de planta que se adaptaran a las condiciones ambientales de la región. De igual manera, se desarrolló un plan de inversión con fondos aportados por el sector público y los agricultores involucrados para la instalación de viveros, plantaciones, empaques y esquemas de comercialización. La meta para 2012 era tener 3.5 mil hectáreas sembradas de arándano y 500 hectáreas de frambuesa, las cuales generarían 159 millones de dólares de producción (Macías, 2014: 208-209).

EntreDiversidades. Revista de Ciencias Sociales y Humanidades, vol. 8, núm. 1 (16), enero-junio 2021. Páginas: 64 - 91 ISSN-e: 2007-7610. https://doi.org/10.31644/ED.V8.N1.2021.A03 
El inicio de esta nueva producción en la región no fue fácil, a causa de las elevadas inversiones y cuidados que estos cultivos demandan. Además, las las dificultades para incursionar en el mercado, derivaron en el desplazamiento de la mayoría de los pequeños y medianos productores, muchos de los cuales perdieron buena parte de su patrimonio. No obstante, la productividad de la zona fue comprobada — particularmente en los valles de Zapotlán, Tuxpan, Zapotiltic y Sayula-, de manera que mientras salían varios productores locales, ingresaban grandes agroempresas trasnacionales y nacionales — como Driscoll's, Berrimex, Dole, Sun Belle, Berries Paradise o Agrícola Cerritos, entre otras-. Estas últimas empezaron a producir por sí mismas o establecieron contratos con agricultores, locales y foráneos, que contaban con mayor nivel de capitalización que sus antecesores — varios de ellos ligados al boom aguacatero- para producir fruta de variedades patentadas, que después empacaban y comercializaban. De igual forma, a partir de 2011 algunos productores de papa de la sierra de Tapalpa establecieron huertas de fresa y de frambuesa, tanto para hacer rotación de cultivos como por las nuevas oportunidades de mercado que estas frutas ofrecían.

Como resultado de lo anterior, las parcelas destinadas a producir distintos tipos de berries en ambientes protegidos —invernaderos, macrotúneles, microtúneles o casas malla sombra ${ }^{7}$ crecieron hasta alcanzar en 2019 un total de 5337 hectáreas. El 57\% de ellas están dedicadas a la producción de frambuesa, el 32\% de arándano, el 9\% de zarzamora, el 1\% de fresa y otro 1\% de planta de fresa (Gráfica 3). La tasa de crecimiento promedio anual en la superficie destinada a cultivar berries fue de $37.1 \%$ entre 2006 y 2019.

\section{Gráfica 3. Superficie sembrada con berries en el sur de Jalisco}

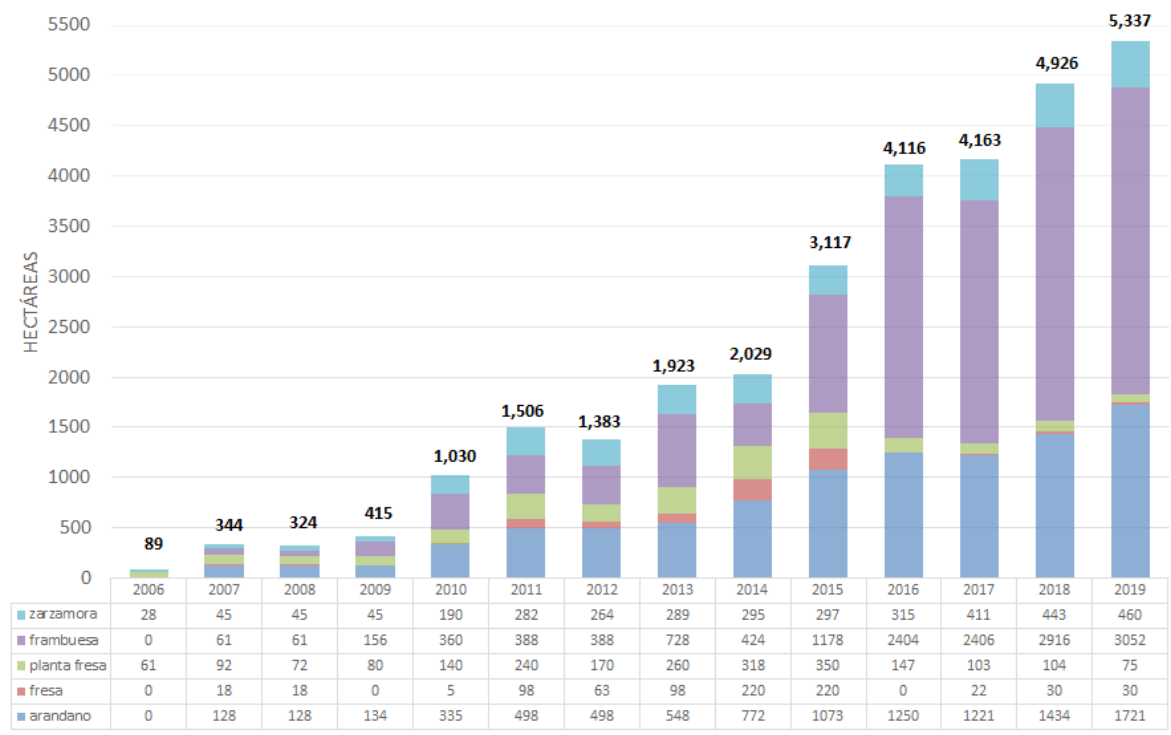

Fuente: Elaborado con base en SADER-SIAP. Anuarios estadísticos de producción agrícola.

\footnotetext{
${ }^{7}$ Los invernaderos son estructuras de metal y plástico cerradas, con ventanas por donde se puede controlar el flujo de aire. Se diferencian de los macrotúneles en que estos están abiertos en los extremos. Los microtúneles son iguales que los macrotúneles, pero con alturas del techo más bajas. Finalmente, en las casas malla sombra se sustituye el plástico por una tela de polietileno u otro material, cuyos pequeńos orificios ofrecen sombra a las plantas.
}

EntreDiversidades. Revista de Ciencias Sociales y Humanidades, vol. 8, núm. 1 (16), enero-junio 2021. Páginas: 64 - 91 ISSN-e: 2007-7610. https://doi.org/10.31644/ED.V8.N1.2021.A03 
En general, durante 2018 la producción de aguacate y berries representaron el 31.8\% del valor de la producción agrícola regional $-18.5 \%$ de aguacate y $13.4 \%$ de berries-, aunque solo ocuparon el $9.7 \%$ de la superficie agrícola cosechada ${ }^{8}-7.4 \%$ de aguacate y $2.3 \%$ de berries(SADER-SIAP, 2020).

En contraste, la superficie destinada a la producción de maíz grano ha disminuido constantemente desde el año 2002, en el que se sembraron 121.5 mil hectáreas $-52.1 \%$ de la superficie sembrada regional-. Comparado con las 83.4 mil hectáreas sembradas en 2019 —34.5\% de la superficie sembrada — supone una disminución del 31.3\% (SADER-SIAP, 2020). Esta reducción es más dramática en municipios donde mayormente ha crecido la producción de aguacate y berries, como Zapotlán el Grande, donde hasta 2018 ha descendido la siembra de maíz grano en 8445 hectáreas respecto a 2003, lo que significa un $91.3 \%$ menos, Tuxpan con -6 530 hectáreas o $58.7 \%$ de disminución, Tamazula con -3 709 hectáreas o 37.5\% menos, Zapotiltic con -3 516 hectáreas o 58.5\% de descenso, Concepción de Buenos Aires con -2 456 hectáreas u 81.9\% de disminución, Mazamitla con -1 925 hectáreas u 82.3\% de reducción, Tonila con -1 218 hectáreas o un descenso de 72.5\% y Manzanilla de la Paz con -1 040 hectáreas u 83.9\% menos.

Los productores de maíz más grandes generalmente han cambiado de cultivo hacia el aguacate, los berries o el maíz forrajero, mientras que muchos de los pequeños agricultores han optado por rentar o vender sus tierras a las empresas frutícolas. En resumen, la agricultura del sur de Jalisco ha tenido un cambio estructural en las cuatro décadas más recientes hacia los agronegocios hortofrutícolas, con fuerte participación de actores extra-regionales. Esto ha generado diversas consecuencias desfavorables para el medio ambiente, como se verá en el siguiente apartado.

\section{Agroempresas hortofrutícolas y daños medioambientales en el sur de Jalisco}

Cuando en 1986 inició la horticultura industrializada en Tapalpa y Sayula, pocos habitantes del sur de Jalisco reflexionaban sobre las consecuencias que en el medio ambiente tendrían la producción de frutas y hortalizas. De hecho, en un principio ambas fueron vistas como una oportunidad para fomentar el desarrollo regional, toda vez que generarían empleo —al ser intensivas en mano de obra-y dinamizarían las economías locales?.

No obstante, conforme fueron creciendo estas formas de producción industrializadas, los impactos negativos también se hicieron más visibles, ocasionando daños incluso a las propias agroempresas, como sucedió en el caso del jitomate. A grandes rasgos, las empresas involucradas en su producción realizaron las siguientes prácticas perjudiciales con el medio ambiente:

\footnotetext{
${ }^{8}$ Otros cultivos agroindustriales que también son importantes en la región son la caña de azúcar -18 585 hectáreas sembradas en 2018- y el agave tequilero -22 396 hectáreas-. Los pastos y praderas ocuparon 44039 hectáreas en 2018 y el maíz forrajero se sembró en 15491 hectáreas.

${ }^{9}$ Como ejemplo, en 1995, cuando empezaba a expandirse el cultivo de jitomate en el valle de Sayula, el periodista local Héctor Villalvazo Chávez (Tzaulan, 22 de abril de 1995: 7) señalaba: “...empresas de este tipo aportan un gran beneficio a la población de la región al generar fuentes de empleo, servicios colaterales, divisas y recursos económicos a la actividad comercial de la localidad".
}

EntreDiversidades. Revista de Ciencias Sociales y Humanidades, vol. 8, núm. 1 (16), enero-junio 2021. Páginas: 64 - 91 ISSN-e: 2007-7610. https://doi.org/10.31644/ED.V8.N1.2021.A03 
- Uso de agroquímicos, en muchas ocasiones indiscriminado, con aplicaciones que incluso se realizaban por vía aérea en sitios cercanos a los centros de población;

- Quema de llantas para generar calor en momentos en que caía una helada y, con ello, disminuir los daños a las plantas y a las frutas. A pesar de que tales acciones derivaban en sanciones municipales por la contaminación provocada, las empresas aceptaban esas multas, pues les costaba menos que ver mermada la cosecha;

- Incendios intencionados y accidentales, provocados con los plásticos utilizados en la horticultura, a los cuales no se les daba el manejo adecuado para que no contaminaran;

- Disminución en el nivel de los acuíferos subterráneos;

- Contaminación del agua por la infiltración y sedimentación de agroquímicos;

- Daños en la calidad de las tierras por su contaminación, debido al: i) uso de agroquímicos; ii) deshecho sin los cuidados adecuados de los envases de plástico que contienen a estos, así como otros plásticos y mangueras utilizados por las empresas; y iii) pérdida de productividad de la tierra por su sobreexplotación;

- Proliferación de plagas y enfermedades en las plantas debido a que no se respetaban los periodos de siembra y veda para romper los ciclos biológicos de las plagas ni se dejaba descansar la tierra. Ello trajo como consecuencia que en 2003 y 2004 el problema de plagas llegara a ser tan grande que hizo prácticamente imposible sembrar jitomate y chile a cielo abierto en el valle de Sayula. ${ }^{10}$

En el caso de la agricultura industrializada de papa también se pueden identificar los anteriores dańos, a los que hay que agregar la deforestación de grandes superficies de bosque para destinarlos a este cultivo. De acuerdo con Santana Aispuro (2014: 45), entre 1971 y 2010 se perdieron en la microcuenca de Tapalpa 3751.6 hectáreas forestales, de las cuales 2358.6 hectáreas fueron destinadas a la agricultura. Aunque no toda esta zona desforestada fue destinada a la producción de papa, sí resultó responsable de un alto porcentaje de la misma.

Dado que el cultivo de papa necesita de suelos arenosos, con requerimientos de surcado profundo y alineación a pendiente para la prevención de hongos patógenos, esta actividad también contribuyó con el arrastre de sedimentos y el aumento de la erosión (Santana Aispuro, 2014: 22). En 2014 se contabilizaron 1200 hectáreas de la microcuenca de Tapalpa con problemas de erosión, lo que representaba el 3.5\% de la superficie total (Santana Aispuro, 2014: 34). Igualmente, disminuyeron los mantos freáticos y hubo contaminación de varios de ellos por los escurrimientos de 35 diferentes tipos de agroquímicos utilizados por los agricultores paperos (Santana Aispuro, 2014: 23).

Pero si la horticultura generó diversas consecuencias negativas en el medio ambiente del sur de Jalisco, la fruticultura industrializada ha ocasionado también esos y otros grandes daños a la naturaleza, que en algunos casos son incluso más graves por el mayor territorio que cubren estos cultivos. Entre los impactos más relevantes se encuentran los siguientes:

\footnotetext{
${ }^{10}$ Para una lectura más detallada sobre los impactos ambientales ocasionados por la producción de jitomate y chile en el valle de Sayula, ver Macías, 2008 y 2011.
}

EntreDiversidades. Revista de Ciencias Sociales y Humanidades, vol. 8, núm. 1 (16), enero-junio 2021. Páginas: 64 - 91 ISSN-e: 2007-7610. https://doi.org/10.31644/ED.V8.N1.2021.A03 


\section{Cambios en los usos de suelo y pérdida de superficie boscosa}

La expansión de las plantaciones de aguacate en el sur de Jalisco se realizó durante los primeros años del siglo XXI mediante la sustitución de cultivos de maíz o caña de azúcar por parte de agricultores locales. Sin embargo, conforme fue creciendo la rentabilidad proporcionada por esta fruta, distintos actores, locales y foráneos, comenzaron a buscar nuevos espacios productivos en las sierras de la región —en alturas entre 1500 y 2500 metros sobre el nivel del mar-, toda vez que en ellas es donde obtienen mayores rendimientos y mejor calidad de fruta. Así, empezaría una agresiva carrera por robarle tierras a los bosques para dedicarlas a la producción de aguacate.

En 2017, el Instituto de Información Estadística y Geográfica del estado de Jalisco (IIEG Jalisco) elaboró un estudio para medir los cambios de uso de suelo en un territorio de 1 millón 279 mil hectáreas, correspondientes a 36 municipios de Jalisco, cuatro de Colima y ocho de Michoacán, que tienen áreas dentro del complejo volcánico de Colima y la Sierra del Tigre; en ese territorio se localizan los 27 municipios del sur de Jalisco.

El estudio, cuya matriz de pérdidas y ganancias se muestra en el Cuadro 1, expone que entre 2003 y 2017 la superficie de bosque disminuyó en 96674.1 hectáreas — 85 052.5 hectáreas de bosque tropical y 11621.6 hectáreas de bosque templado_-, que significaron el 11.2\% de la superficie boscosa existente en 2003. Tal porcentaje resulta dramático si se considera que sucedió en un periodo de apenas 14 años.

En contrapartida, la superficie agrícola en ambas sierras se incrementó en 82943 hectáreas, de las cuales, 27566 fueron para huertos, 18126 para agricultura de temporal, 16095 para agricultura de riego, 18121 para pastizales y 3005 ocupadas por invernaderos.

EntreDiversidades. Revista de Ciencias Sociales y Humanidades, vol. 8, núm. 1 (16), enero-junio 2021. Páginas: 64 - 91 ISSN-e: 2007-7610. https://doi.org/10.31644/ED.V8.N1.2021.A03 


\section{Cuadro 1. Cambios de uso de suelo en municipios con superficie en el Macizo del Volcán Colima y Sierra del Tigre, entre 2003 y 2017}

\begin{tabular}{|c|c|c|c|c|c|c|c|c|c|c|c|c|}
\hline & \begin{tabular}{|l|} 
Cuerpos \\
de Agua
\end{tabular} & \begin{tabular}{|c|} 
Vegetación \\
Hidrófila
\end{tabular} & $\begin{array}{c}\text { Agricultura } \\
\text { Riego }\end{array}$ & Huertos & $\begin{array}{c}\text { Bosque } \\
\text { Templado }\end{array}$ & \begin{tabular}{l|} 
Bosque \\
Tropical
\end{tabular} & \begin{tabular}{|c|} 
ggricultura \\
Temporal
\end{tabular} & \begin{tabular}{|l|} 
Pastizal \\
\end{tabular} & Invernaderos & $\begin{array}{l}\text { Desprovisto } \\
\text { de Veg. }\end{array}$ & \begin{tabular}{|c|} 
Pradera \\
Alta \\
Montaña
\end{tabular} & $\begin{array}{c}\text { Area } \\
\text { Urbana }\end{array}$ \\
\hline $\begin{array}{l}\text { Cuerpos de } \\
\text { Agua }\end{array}$ & 0.0 & $-1,599.9$ & $-1,016.9$ & 0.0 & -75.6 & -295.4 & $-2,033.4$ & 12.7 & 0.0 & 587.5 & 0.0 & 14.5 \\
\hline $\begin{array}{l}\text { Vegetación } \\
\text { Hidrófila }\end{array}$ & 1,599.9 & 0.0 & -10.4 & 0.0 & -21.6 & -140.9 & $-1,219.9$ & -10.5 & 0.0 & 626.0 & 0.0 & 11.8 \\
\hline \begin{tabular}{|l} 
Agricultura \\
Riego
\end{tabular} & $1,016.9$ & 10.4 & 0.0 & 614.2 & $-3,466.2$ & $-3,279.9$ & \begin{tabular}{|l|}
$-12,048.9$ \\
\end{tabular} & -472.7 & 626.5 & -67.4 & 0.0 & 972.5 \\
\hline Huertos & 0.0 & 0.0 & -614.2 & 0.0 & $-6,188.9$ & $-6,293.8$ & \begin{tabular}{|l|}
$-13,998.8$ \\
\end{tabular} & -472.5 & 1.4 & 0.0 & 0.0 & 0.9 \\
\hline $\begin{array}{l}\text { Bosque } \\
\text { Templado }\end{array}$ & 75.6 & 21.6 & $3,466.2$ & $6,188.9$ & 0.0 & 0.0 & 129.6 & $1,038.8$ & 16.5 & 88.6 & 220.0 & 375.9 \\
\hline Bosque Tropical & 295.4 & 140.9 & $3,279.9$ & $6,293.8$ & 0.0 & 0.0 & \begin{tabular}{|l|}
$44,067.5$ \\
\end{tabular} & $39,538.0$ & 78.3 & 86.9 & 18.2 & $1,253.7$ \\
\hline \begin{tabular}{|l} 
Agricultura \\
Temporal
\end{tabular} & $2,033.4$ & $1,219.9$ & $12,048.9$ & $13,998.8$ & -129.6 & $-34,067.5$ & 0.0 & $-21,019.0$ & $2,237.0$ & -98.0 & 0.0 & $5,649.8$ \\
\hline Pastizal & -12.7 & 10.5 & 472.7 & 472.5 & $-1,038.8$ & $-39,538.0$ & $21,019.0$ & 0.0 & 11.8 & 4.3 & 0.0 & 477.9 \\
\hline Invernaderos & 0.0 & 0.0 & -626.5 & -1.4 & -16.5 & -78.3 & $-2,237.0$ & -11.8 & 0.0 & -62.3 & 0.0 & -1.7 \\
\hline $\begin{array}{l}\text { Desprovisto de } \\
\text { Veg. }\end{array}$ & -587.5 & -626.0 & 67.4 & 0.0 & -88.6 & -86.9 & 98.0 & -4.3 & 62.3 & 0.0 & 129.0 & 60.4 \\
\hline $\begin{array}{l}\text { Pradera Alta } \\
\text { Montaña }\end{array}$ & 0.0 & 0.0 & 0.0 & 0.0 & -220.0 & -18.2 & 0.0 & 0.0 & 0.0 & -129.0 & 0.0 & 0.0 \\
\hline Area Urbana & -14.5 & -11.8 & -972.5 & -0.9 & -375.9 & $-1,253.7$ & $-5,649.8$ & -477.9 & 1.7 & -60.4 & 0.0 & 0.0 \\
\hline Total & $4,406.5$ & -834.5 & $16,094.7$ & $27,566.0$ & $-11,621.6$ & $-85,052.5$ & $18,126.4$ & $18,120.7$ & $3,035.4$ & 976.2 & 367.1 & $8,815.6$ \\
\hline
\end{tabular}

* Contempla 1,279,041 hectáreas, de 36 municipios de Jalisco, cuatro de Colima y 8 de Michoacán. Los municipios de Jalisco son: Amacueca, Juchitán (parcial), Techaluta, Sayula, Tonaya (parcial), Tapalpa, Valle de Juárez, Ejutla (parcial), Atoyac, Concepción de B. A., Gómez Farías, La Manzanilla de la P., Mazamitla, Tizapán el Alto, Teocuitatlán, Chiquilistlán, Tuxcueca (parcial), Tecolotlán (parcial), Atemajac de B., Zacoalco (parcial), Chapala (parcial), Jocotepec (parcial), Poncitlán (parcial), San Gabriel, Zapotiltic, Tuxcacuesco (parcial), Zapotlán el Grande, Quitupan, Pihuamo (parcial), Zapotitlán de V., Tonila, Tuxpan, Tecalitlán (parcial), Santa María del O., Tamazula, Jilotlán (parcial) y Tolimán. De Colima son parcialmente Villa de Álvarez, Comala, Minatitlán y Cuauhtémoc. De Michoacán son Tocumbo (parcial), Cotija (parcial), Jiquilpan, Villamar (parcial), Marcos Castellanos, Sahuayo, Cojumatlán de Régules y Venustiano Carranza (parcial).

Fuente: Elaborado con base en datos de IIEG Jalisco (2017) Mapa de Frontera Forestal del Complejo Volcánico de Colima y Cobertura de Vegetación de la Sierra del Tigre.

Al hacer el análisis exclusivamente sobre un territorio de 456895 hectáreas, pertenecientes a nueve municipios del sur de Jalisco ${ }^{11}$, los datos muestran que en el mismo periodo la superficie boscosa disminuyó en 28145 hectáreas — 8.6\% de pérdida—, de las cuales 9010 hectáreas fueron de bosque templado y 19135 de bosque tropical. Por su parte, la superficie de huertos creció en 18112 hectáreas, mientras los pastizales lo hicieron en 7128 hectáreas, la agricultura de riego en 5203 hectáreas y los invernaderos en 1806 hectáreas (IIEG, 2017).

${ }^{11}$ Zapotlán el Grande, Zapotiltic, Tamazula, Quitupan, Mazamitla, Concepción de Buenos Aires, Gómez Farías, San Gabriel y Sayula.

EntreDiversidades. Revista de Ciencias Sociales y Humanidades, vol. 8, núm. 1 (16), enero-junio 2021. Páginas: 64 - 91 ISSN-e: 2007-7610. https://doi.org/10.31644/ED.V8.N1.2021.A03 
Dos aspectos son de reconocerse de acuerdo con los datos del Cuadro 1. Primero, que la mayor parte de la pérdida de bosque, principalmente tropical, no fue consecuencia directa de la instalación de huertas de aguacate o invernaderos de berries, sino que se debió al incremento de los pastizales y de la agricultura de temporal. Segundo, que más de la mitad del crecimiento de las huertas de aguacate fue a costa de áreas previamente destinadas a agricultura de temporal, donde se sembraba principalmente maíz y caña de azúcar.

Sin embargo, es también evidente que en esos 14 años se cambiaron 12483 hectáreas de bosque para instalar huertas aguacateras, ocasionando disminución de mantos freáticos, así como afectaciones a la flora y fauna originarias. Además, es importante tener en cuenta que a la transformación de bosque en agricultura de temporal puede seguir en poco tiempo la sustitución de esta por huertas agroindustrializadas. Igualmente, debe considerarse que la producción de aguacates y berries demandan grandes cantidades de agua y otros insumos, de manera que su impacto ambiental es varias veces más grande que el que puedan ocasionar los pastizales o los cultivos de temporal.

La pérdida de bosque está relacionada con actuaciones legales de cambios de uso de suelo — muchas de ellas polémicas ${ }^{12}$ — , pero principalmente utilizando la vía ilegal. En este sentido, a pesar de que desde 2011 son mínimas las autorizaciones otorgadas por la Secretaría de Medio Ambiente y Recursos Naturales para cambio de uso de suelo en bosques del sur de Jalisco - entre ellas, 176 hectáreas en San Gabriel y 38 hectáreas en Zapotlán el Grande (Rodríguez Pinto, 2019)_, solo entre ese año y 2017 se calculan en más de tres mil las hectáreas de bosque que fueron convertidas de forma ilegal en huertas aguacateras.

Uno de los principales mecanismos utilizados para justificar los cambios de uso de suelo son los incendios intencionados en el bosque. Según el registro histórico de incendios, generado por la Secretaría de Medio Ambiente y Desarrollo Territorial de Jalisco (mencionado por Rodríguez Pinto, 2018), entre 2009 y 2017 se registraron 428 incendios forestales intencionados en Jalisco, de los cuales el 56\% fueron en la región sur del estado. Esta situación, lejos de corregirse, se agravó en los años siguientes, hasta llegar al extremo en 2019, cuando se vieron afectadas 12177 hectáreas boscosas en las inmediaciones del nevado de Colima (Gutiérrez, 2019), precisamente la zona con mayor crecimiento en la instalación de huertas de aguacate.

La tala inmoderada de bosque y los incendios intencionados provocaron en junio de 2019 un desastre en la cabecera municipal de San Gabriel, cuando el desbordamiento del río Salsipuedes debido a las fuertes lluvias — aunque hay quien afirma que fue el desbordamiento de una presa construida por productores de aguacate- ocasionó que se desplazaran por la sierra grandes cantidades de troncos de pino que habían sido derrumbados durante las semanas previas, cayendo en la zona urbana y causando importantes daños a viviendas, así como la muerte de varias personas. Este suceso se ha considerado el primer desastre humano en el sur de Jalisco generado por la obsesión de convertir bosque en plantaciones de aguacate.

\footnotetext{
${ }^{12}$ Un caso relevante al respecto sucedió en 2011, cuando el entonces delegado en Jalisco de la Secretaría de Medio Ambiente y Recursos Naturales, José de Jesús Álvarez Carrillo, se vio obligado a presentar solicitud de licencia para dejar su cargo a efecto de ser investigado por autorizar a particulares la tala de 36 hectáreas en el municipio de Mazamitla, para ser plantadas con aguacate (Rodríguez Soto, 2011). Entre 2009 y 2010, este mismo delegado había autorizado el derribo de 455 hectáreas de pino en el sur de Jalisco para instalar plantaciones aguacateras (Méndez, 2011).
}

EntreDiversidades. Revista de Ciencias Sociales y Humanidades, vol. 8, núm. 1 (16), enero-junio 2021. Páginas: 64 - 91 ISSN-e: 2007-7610. https://doi.org/10.31644/ED.V8.N1.2021.A03 
Otra estrategia utilizada por los aguacateros para sustituir el bosque consiste en dejar una "cortina" de pinos para burlar la vigilancia oficial, pero dentro de la finca plantar aguacates o sembrar plantas de aguacate por debajo de las ramas de los pinos, y poco a poco derribar estos conforme vayan creciendo aquellos.

Sea por la vía legal o clandestina, el hecho es que la superficie boscosa en el sur de Jalisco está siendo severamente afectada por una agricultura industrializada que responde a intereses y demandas externas a la región, lo que en el corto, mediano y largo plazo terminará por causar graves daños a este territorio, a sus habitantes y a su entorno natural.

\section{Disminución de acuíferos y deterioro en la calidad de sus aguas}

Este fenómeno es una de las consecuencias más graves provocadas por la pérdida de superficie boscosa, ya que dicho cambio para instalar huertas aguacateras afecta los niveles de agua por dos razones:

1) Porque mientras el pino es la especie por excelencia para retener el agua de la lluvia y llevarla al subsuelo, el árbol de aguacate utiliza el agua para madurar su fruto, de manera que cada árbol necesita un promedio aproximado de 100 a 200 litros de agua entre cuatro y cinco veces a la semana. De esta forma, el agua que llega al subsuelo es menor, disminuyendo también el flujo de líquido para ríos, lagos y lagunas.

2) Los productores de aguacate, para alcanzar un nivel de producción exigido por los mercados, tanto en cantidad como en calidad, necesitan establecer obras de infraestructura de riego. Por ello, muchas de las huertas instaladas en el sur de Jalisco hoy cuentan con membranas para captar el agua de lluvia — también conocidas como ollas, aljibes agrícolas, bordos o cajas de agua-, perjudicando las posibilidades de recarga de los mantos acuíferos. De acuerdo con Digna Carrillo (2019), en la microcuenca La Difunta, ubicada en la ladera nororiente del complejo volcánico de Colima, se localizaron 103 membranas en 2019 para dar servicio a 3069 hectáreas de aguacate. Si se considera que esta superficie apenas representa alrededor de una novena parte de la superficie aguacatera regional, y que cada uno de estos depósitos tiene capacidad para almacenar hasta tres millones de litros de agua ${ }^{13}$, se puede estimar que los productores de aguacate extraen o no dejan llegar a los acuíferos subterráneos de la región por esta vía aproximadamente 2781 millones de litros de agua cada año.

Las consecuencias negativas de lo anterior son evidentes para el acuífero subterráneo de Ciudad Guzmán, cuyo territorio abarca la zona de mayor crecimiento en el número de huertas de aguacate e invernaderos. Como se puede observar en el Cuadro 2, en 2007 el acuífero tenía un superávit de agua de $135.08 \mathrm{Mm}^{3}$, cuando en la región había 4611 hectáreas de aguacate; esta cantidad le permitía ser el segundo acuífero subterráneo con mayores reservas de agua en Jalisco. Sin embargo, para 2015 la situación ya se había revertido, mostrando un déficit de $20.95 \mathrm{Mm}^{3}$.

${ }^{13}$ Porque, además, en muchos casos las ollas también son abastecidas con agua extraída de pozos profundos.

EntreDiversidades. Revista de Ciencias Sociales y Humanidades, vol. 8, núm. 1 (16), enero-junio 2021. Páginas: 64 - 91 ISSN-e: 2007-7610. https://doi.org/10.31644/ED.V8.N1.2021.A03 
Cuadro 2. Estadísticas de agua en el Acuífero de Ciudad Guzmán

\begin{tabular}{|c|c|c|c|c|}
\hline \multicolumn{5}{|c|}{ Millones de metros cúbicos anuales } \\
\hline Año & $\begin{array}{c}\text { Recarga Media } \\
\text { Anual }\end{array}$ & Extracción & $\begin{array}{c}\text { Disponibilidad } \\
\text { Media Anual }\end{array}$ & Déficit \\
\hline 2007 & 266.0 & 130.92 & 135.08 & 0.00 \\
\hline 2009 & 266.1 & 163.26 & 102.84 & 0.00 \\
\hline 2015 & 266.1 & 287.05 & 0.00 & -20.95 \\
\hline 2018 & 266.1 & 293.02 & 0.00 & -26.92 \\
\hline
\end{tabular}

Fuente: Elaborado con base en datos del Diario Oficial de la Federación,

13 de agosto de 2007; 28 de agosto de 2009; 20 de abril de 2015; 4 de enero de 2018.

A pesar de ello, en los años siguientes la Comisión Nacional del Agua (CONAGUA) siguió otorgando concesiones a los empresarios agrícolas para la explotación del acuífero. De acuerdo con datos del Registro Público de Derechos del Agua, entre enero de 2015 y octubre de 2019 se entregaron 122 concesiones en este acuífero, con un volumen de extracción de 19.42 millones de metros cúbicos (CONAGUA, 2019). Tal situación provocó que, de acuerdo con los datos oficiales más recientes, correspondientes a enero de 2018, el nivel de extracción de agua en el acuífero de Ciudad Guzmán se incrementara un 124\% respecto de los valores de 2007, de manera que en ese año el déficit ascendió a 26.92 millones de metros cúbicos (Cuadro 2). Es evidente que de seguir creciendo las huertas de aguacate los niveles de déficit continuarán deteriorándose, poniendo en riesgo la vida en la región.

El abatimiento del acuífero de Ciudad Guzmán puede generar otras consecuencias negativas para los habitantes del sur de Jalisco. Una de ellas tiene que ver con la sismicidad que caracteriza a este territorio, atravesado por diversas fallas y fracturas tectónicas. Al respecto, un caso significativo es Ciudad Guzmán, principal zona urbana del sur de Jalisco, edificada sobre varias de estas fracturas y fallas, derivadas del contacto entre un bloque levantado, como es la Sierra del Tigre, y el bloque hundido de la depresión de Zapotlán (Zamudio, et al., 2016). El impacto sísmico en la ciudad y áreas colindantes puede agravarse por la sobreexplotación del acuífero de Ciudad Guzmán, pues, como señala el Servicio Geológico Mexicano (2017), la acción erosiva de las aguas subterráneas al interior de la corteza va dejando un vacío que termina por ceder ante el peso de la parte superior, generándose vibraciones sísmicas de poca extensión pero que pueden resultar de fuerte intensidad. En 2012 y 2019 sucedieron dos sismos muy localizados, que bien pudieran derivarse del abatimiento acuífero. Aunque ambos fenómenos solo causaron agrietamientos en casas y en la infraestructura pública, pueden ser el preámbulo de eventos de mucha mayor gravedad, ante los cuales los habitantes de Ciudad Guzmán están en constante exposición.

EntreDiversidades. Revista de Ciencias Sociales y Humanidades, vol. 8, núm. 1 (16), enero-junio 2021. Páginas: 64 - 91 ISSN-e: 2007-7610. https://doi.org/10.31644/ED.V8.N1.2021.A03 
Los daños a la cantidad y calidad de agua en el sur de Jalisco no se limitan a la sobreexplotación de los acuíferos subterráneos, sino también a las aguas superficiales. Tal es el caso de la Laguna de Zapotlán, considerada el principal recurso hídrico en el sur de Jalisco, tanto porque es proveedora de agua para Ciudad Guzmán y otras localidades aledańas, como por ser un factor importante en la regulación climática regional.

La Laguna de Zapotlán forma parte de la Cuenca endorreica de Zapotlán, localizada entre la Sierra del Tigre y el Parque Nacional Nevado de Colima (DOF, 2013). Tiene una superficie promedio de entre 900 y 1340 hectáreas, con una profundidad promedio de 4.75 metros y capacidad máxima de almacenaje de hasta $27 \mathrm{Mm}^{3}$ (Michel Parra, et al., 2005). Tiene una precipitación media anual de $812 \mathrm{~mm}$, con evaporación promedio de $17.7 \mathrm{Mm}^{3}$ (Michel Parra, et al., 2005). Su ciclo natural de abastecimiento es a través de arroyos y escurrimientos de la vertiente occidental de la Sierra del Tigre y de los Manzanillos, así como de la vertiente meridional de la Serranía Usmajac, la vertiente Oriental de la Sierra de la Media Luna y la falda septentrional del Nevado de Colima (García de Alba, 2006: 77; Aquainteracciones, 2009: 9). En cuanto al aprovechamiento de sus aguas, de acuerdo con la Comisión Estatal del Agua de Jalisco (CEAS, 2015: 19), el 47.2\% es para servicio público urbano, el 38.9\% para servicios y el $13.5 \%$ para uso agrícola. Dicho organismo señalaba desde 2015 que la condición de la Laguna de Zapotlán es de "sin disponibilidad" de agua para nuevas actividades.

Desde el siglo XX, la Laguna de Zapotlán ha sido severamente perjudicada por diversos procesos, tales como: i) el crecimiento urbano de Ciudad Guzmán y de las actividades agrícolas municipales, los cuales provocaron que su área disminuyera de 2800 hectáreas en 1920 a 1340 hectáreas que se le reconocían en 2014 (García de Alba, entrevistado por Carrillo Armenta, 2004: 18); ii) su contaminación por el proceso de drenaje de aguas residuales de Ciudad Guzmán, así como por el arrastre de agroquímicos utilizados en la agricultura colindante; iii) el asolvamiento de su vaso lacustre por el arrastre de material proveniente de las zonas serranas deforestadas; iv) la desaparición de algunos cauces que fluían hacia la laguna, pero que se fueron borrando por las actividades de labranza; v) la construcción de vías de transporte que atravesaron la laguna, tales como el tramo de la carretera federal Guadalajara-Ciudad Guzmán o el libramiento carretero.

Estos perjuicios al embalse acuífero fueron tan graves que a finales del siglo XX diversos actores de la región iniciaron un proceso para su recuperación, lo que los llevaría a gestionar en 2004 su reconocimiento como Humedal de Importancia Internacional o Sitio Ramsar, meta alcanzada el 5 de junio de 2005 (Michel Parra y Guzmán Arroyo, 2012).

A pesar de ello, la expansión de la fruticultura y la intensificación en el uso de insumos externos para su desarrollo han dado al traste con los esfuerzos de recuperación de la laguna, agravando incluso muchos de sus problemas. Por un lado, la deforestación de las zonas serranas y los procesos de erosión provocan un recrudecimiento en el azolvamiento de la laguna, al grado de que a partir de 2014 esta se ha desbordado, extendiéndose en superficie, pero disminuyendo su capacidad de almacenamiento de agua. Paradójicamente, ello ha provocado daños a parcelas aledañas que frecuentemente se inundan y pierden gran parte de su producción.

Por otro lado, las huertas de aguacate y la instalación excesiva de invernaderos en los alrededores de la laguna también generan un elevado flujo de fertilizantes y agroquímicos hacia

EntreDiversidades. Revista de Ciencias Sociales y Humanidades, vol. 8, núm. 1 (16), enero-junio 2021. Páginas: 64 - 91 ISSN-e: 2007-7610. https://doi.org/10.31644/ED.V8.N1.2021.A03 
esta, provocando la grave contaminación de sus aguas, lo que pone en riesgo la vida de las especies de flora y fauna que la habitan, así como el crecimiento desmedido de lirio y la consecuente pérdida de oxígeno en el vaso lacustre.

Ambas situaciones, adicionadas al arrastre de aguas negras urbanas y la desaparición o contaminación de diversos arroyos y escurrimientos, hacen altamente vulnerable a la laguna, lo cual constituye un aspecto delicado para la región, toda vez que además de ser un ente regulador del clima sirve de protección contra tormentas y alberga diversas especies, algunas de ellas en peligro de extinción — como la musaraña, el halcón mexicano, el murciélago trompudo, la víbora de cascabel, la tortuga Kinosternon, la rana de patas largas o la cigüeńa americana—.

\section{Afectación a la flora y fauna}

El sur de Jalisco es una importante zona productora de miel, al aportar en 2018 el 3.1\% de la producción nacional. Sin embargo, desde principios de la segunda década del siglo XXI, los apicultores de la región han sufrido una creciente mortandad de abejas en sus colmenas (Salvador y Maldonado, 2012), situación que fue agravándose paulatinamente hasta que el 5 de abril de 2016 hubo una muerte masiva de estos insectos en los municipios de Zapotlán el Grande, Tamazula, San Gabriel y Zapotiltic (Velazco, 2016). En ese momento se calculó en más de mil las colmenas con hasta el $90 \%$ de sus abejas muertas, de manera que la suma de muertes era de varios millones, pues cada colmena contiene entre 70 y 80 mil individuos. Esta situación se repetiría en los meses siguientes, de manera que en julio de 2017 se cuantificó que las colmenas existentes en Jalisco habían descendido un 40\% respecto de las 280 mil que se encontraban dos ańos atrás, además de que la producción de miel por colmena había disminuido de un promedio de 40 litros a solo 12 litros anuales (Bareño Domínguez, 2017).

Para los apicultores afectados, al igual que para varios especialistas, la muerte masiva de abejas en la región se debió al envenenamiento ocasionado por los productores de aguacate y maíz, al haber usado pesticidas piretroides, además de Fipronil. ${ }^{14}$ Tal aseveración se respaldó en el hecho de haber encontrado en las abejas muertas restos de cipermetrina y neonicotinoides, ingredientes de estos compuestos químicos (Sepúlveda Velázquez, 2016), que son muy dañinos para estos animales (Martin-Culma y Arenas-Suárez, 2018: 237).

Aunque las muertes de abejas es, por ahora, el caso más difundido sobre la afectación de la hortofruticultura a la fauna regional, existen también otros dańos a las especies vegetales y animales. Uno de ellos es el relacionado con la disminución de plantas de maguey pulquero de la variedad ceniza, que anteriormente existían en buena cantidad en las sierras de la región, lo que permitía a varios productores locales mantenerse con la producción de pulque. No obstante, con la llegada de las aguacateras, principalmente a partir de 2012, esta planta fue paulatinamente desterrada de tales espacios, al representar, según algunos productores de aguacate, un problema

\footnotetext{
${ }^{14}$ Los piretroides son sustancias químicas compuestas por moléculas con actividad insecticida, que se obtienen por síntesis a efecto que tuvieran una estructura similar a las piretrinas (sustancias activas insecticidas naturales, de origen vegetal). Por su parte, el Fipronil es un insecticida de amplio espectro que interrumpe el sistema nervioso central de los insectos mediante el bloqueo de los canales del ácido $\gamma$-aminobutírico y glutamato (GluCl).
}

EntreDiversidades. Revista de Ciencias Sociales y Humanidades, vol. 8, núm. 1 (16), enero-junio 2021. Páginas: 64 - 91 ISSN-e: 2007-7610. https://doi.org/10.31644/ED.V8.N1.2021.A03 
para la inocuidad de su producto, toda vez que, argumentan, el maguey atrae ardillas, gusanos y otros animales supuestamente nocivos para el aguacate.

De igual manera, se ha identificado un proceso de migración del bosque por parte de distintas especies animales que son desplazadas de su lugar de origen, viéndose obligadas a buscar otras áreas forestales en las cuales deben competir con otros individuos de su misma especie o de otras. Además, algunas plantas nativas pueden terminar sucumbiendo, ya sea por la acción intencional de los aguacateros, por los agroquímicos que aplican o por los cambios en el entorno.

Pero también los propios productores de aguacate tienen riesgos ante su acción invasora, pues la sustitución de los pinos por árboles distintos desequilibra el balance biológico del suelo, potenciando determinados hongos que durante siglos han convivido con el bosque sin afectar a sus árboles, pero que sí atacan a las nuevas especies ajenas al ecosistema. Es el caso del hongo Armillaria mellea, el cual provoca la pudrición del sistema radicular de las plantas, impidiéndoles absorber agua y nutrientes del suelo, hasta ocasionar su muerte por inanición (Téliz y Mora, 2008: 204). En México, de acuerdo con Daniel Téliz (2008), este hongo ya ha dańado plantaciones ubicadas en zonas boscosas en Morelos y en el Estado de México, de ciruelo y durazno respectivamente. Además, cada vez son más frecuentes las afecciones en huertas de aguacate en otras partes del país (Michua-Cedillo, et al., 2017).

\section{Uso de cañones antigranizo}

Conforme se intensifica la producción de aguacate y berries han aparecido en la región los llamados cańones antigranizo, cuya supuesta función es proteger a las plantas ante tormentas que conlleven la caída de granizo. Estos aparatos funcionan a través de explosiones de gas acetileno, nitrógeno, aire y otras sustancias, con ondas de choque que viajan a la velocidad del sonido - $1200 \mathrm{~km}$ por hora, con fuerza de $332 \mathrm{~kg}$ por $\mathrm{cm}^{2}$ - para empujar aire caliente hacia la atmósfera. Con ello, el calor asciende hasta 15 mil metros de altura, de manera que al llegar a la nube provoca un choque de aire caliente y frío; con ello, se cambia la polaridad de la nube y se modifican las condiciones de precipitación, transformando el granizo en líquido o granizo blando.

Aunque el efecto anterior no está científicamente comprobado — estudios realizados en Suiza en la década de 1980 mostraron estadísticamente que nada más existe un 35\% de probabilidad de que la acción de los cañones disminuya la incidencia de granizo, por el 65\% de que incluso la incremente (Pérez, 2018)—, los cañones antigranizo siguen siendo utilizados por los agricultores de diversas partes del mundo. En las huertas e invernaderos de aguacate y berries en la región estos implementos aparecieron aproximadamente en 2011, de manera que para 2015 ya se hablaba de la existencia mínima de 39 cañones (García, 2015). Dado que en ese año el temporal de lluvia resultó raquítico, afectando a productores de maíz, frijol y otros cultivos, estos acusaron a los cañones de ser la causa del fenómeno meteorológico, pues, según ellos, las ondas de iones que emitían los cañones no solo transformaban el granizo en agua, sino que también generaron procesos de evaporación que impedían la caída de precipitaciones.

Las movilizaciones de protesta contra el uso de cańones antigranizo crecieron en los siguientes meses, lo que obligó al Congreso del Estado de Jalisco a establecer, en marzo de 2016, un punto de acuerdo para suspender su uso en el estado, en tanto se realizaban las modificaciones necesarias

EntreDiversidades. Revista de Ciencias Sociales y Humanidades, vol. 8, núm. 1 (16), enero-junio 2021. Páginas: 64 - 91 ISSN-e: 2007-7610. https://doi.org/10.31644/ED.V8.N1.2021.A03 
a la Ley de Equilibrio Ecológico y Protección al Medio Ambiente de Jalisco. No obstante, en los años siguientes se siguieron empleando estos artefactos en el sur de Jalisco, lo que derivó en nuevas protestas durante 2018 y 2019. En este último año, el gobierno municipal de Sayula fue el primero en la región en prohibirlos definitivamente.

Independientemente de que no esté científicamente comprobada la efectividad de estos implementos, ni tampoco que tal tecnología altere las condiciones atmosféricas y el ciclo del agua (Estrada Ávalos, et al., 2018), la resistencia mostrada por los agricultores del sur de Jalisco no inmiscuidos en la producción frutícola pone en evidencia el enfrentamiento social que estas industrias terminan provocando en la región, al generar elevadas utilidades privadas a expensas de grandes costos para la sociedad y para la naturaleza.

\section{Conclusiones}

Cuando en una región inicia una actividad como la producción agrícola industrializada de frutas y hortalizas prometiendo grandes beneficios económicos para sus habitantes, poca gente reflexiona sobre los costos que a la larga la misma puede generar en el territorio. Por ello, en un principio las empresas que se involucran suelen ser vistas como detonantes para el desarrollo regional, de manera que se les facilita sus procesos de instalación y crecimiento. Esta situación, efectivamente, se ratifica en tales territorios, sobre todo en los años de mayor expansión de la actividad hortofrutícola, pues se observa en las zonas urbanas aledañas a las áreas de producción, el crecimiento de proveedores de maquinaria, insumos y materias primas para la agricultura intensiva, así como de intermediarios dedicados a la comercialización de su producción. Igualmente, existe un incremento de las oportunidades de empleo que incluso atraen población de otros territorios, manifestándose en la dinámica urbana.

En el sur de Jalisco tales efectos económicos efectivamente se han vivido, tanto en los años noventa en la ciudad de Sayula y otras poblaciones urbanas del valle, como en la actualidad en la principal ciudad de la región que es Ciudad Guzmán. En esta, existe un importante dinamismo económico, reflejado en el crecimiento del 25\% de las unidades económicas existentes en el municipio de Zapotlán el Grande entre 2004 y 2019, así como en el incremento de empresas dedicadas a actividades vinculadas con la producción agrícola industrializada: se establecieron 14 nuevas empresas en comercio al por mayor de frutas y verduras frescas; las empresas dedicadas el comercio al por mayor de fertilizantes, plaguicidas y semillas para siembra pasaron de 10 a 38 en ese periodo, mientras que las dedicadas al comercio al por mayor de maquinaria y equipo agropecuario, forestal y para la pesca se incrementaron de 10 a 17 (INEGI, 2004; 2019).

Igualmente, las oportunidades de empleo en la agricultura regional han crecido sustancialmente, aunque sea principalmente a través trabajos eventuales. En 2019, mientras que la región sur aportaba el 4\% del empleo de Jalisco, registrado ante el Instituto Mexicano del Seguro Social (IMSS), los porcentajes de aportación se incrementaban a $24.4 \%$ en empleo permanente en el campo y 53.4\% en empleo temporal en el campo (IMSS, 2020). Esta creciente oferta laboral agropecuaria se refleja también en el crecimiento urbano, como se demuestra en el hecho de que en los años recientes se han desarrollado varios nuevos fraccionamientos en Ciudad

EntreDiversidades. Revista de Ciencias Sociales y Humanidades, vol. 8, núm. 1 (16), enero-junio 2021. Páginas: 64 - 91 ISSN-e: 2007-7610. https://doi.org/10.31644/ED.V8.N1.2021.A03 
Guzmán, dos de los cuales están conformados por viviendas multifamiliares para personas de ingresos medios y bajos, un tipo de construcción anteriormente inexistente en esta ciudad.

Pero si la relevancia económica de la agricultura hortofrutícola industrializada está fuera de toda duda, al ser cultivos de alto valor agregado e intensivos en mano de obra, resulta fundamental contrastar estos beneficios con los daños que con el correr de los años se hacen manifiestos en el medio ambiente, para realmente señalar si es o no una actividad que impulse una mejor calidad de vida en las regiones productoras. La evidencia empírica en las experiencias hortícola y frutícola en el sur de Jalisco muestra que, mientras la mayor parte de los beneficios económicos se concentran en unos pocos actores vinculados con esta agricultura, los perjuicios a la naturaleza suelen ser severos, incrementándose con ello la vulnerabilidad de los distintos seres que viven en ella, incluyendo por supuesto al ser humano.

En el caso particular de la producción de aguacates y berries en la región, y tras dos décadas de actividad, este documento ha mostrado consecuencias preocupantes, como son la pérdida de importantes superficies de bosque, la acelerada disminución y contaminación de mantos freáticos y las muertes masivas de distintas especies de fauna y flora. Tales fenómenos, sin duda, ponen en riesgo los equilibrios territoriales actuales, de manera que en el futuro pudiera haber lugares semidesérticos en lo que hoy son zonas agroproductoras fértiles, ciudades y pueblos con escasez de agua, incremento en la temperatura promedio y menores defensas ante las previsibles consecuencias del cambio climático global, mayor vulnerabilidad de la población ante fenómenos telúricos, así como pérdida de oportunidades para otras formas de producción de alimentos, etc.

Esta situación de creciente vulnerabilidad debe ser frenada y revertida lo más pronto posible. Por ello, resulta urgente tomar medidas correctivas por parte de los gobiernos en sus distintos órdenes, así como de la sociedad y de las propias empresas, antes de que sea demasiado tarde y lo que hoy se ven como crisoles de valles y montañas generosas en el sur de Jalisco se conviertan en desiertos hostiles a la vida.

\section{Bibliografía citada}

Alwang, Jeffrey, Paul B. Siegel y Steen L. Jorgensen (2001). Vulnerability: a View from Different Disciplines. Discussion Paper Series No. 0115. Social Protection Unit, Washington DCUSA: World Bank. También disponible en: http://documents1.worldbank.org/curated/ en/636921468765021121/pdf/multi0page.pdf

Aquainteracciones (2009). Estudio socioeconómico, biológico y pesquero y plan de manejo del embalse "Laguna de Zapotlán", municipio de Ciudad Guzmán, Jalisco. Informe final. GuadalajaraMéxico: Aquainteracciones. También disponible en: http://www.zapotlan.gob.mx/ Documentos/General/ecologiaLagunaInformeEstudio201004.pdf

Bareño Domínguez, Rosario (2017). "Abejas en peligro de extinción por insecticidas; disminuyó $40 \%$ producción de miel en Jalisco". El Sol de México, [en línea]. Disponible en: https://www.elsoldemexico.com.mx/finanzas/abejas-en-peligro-de-extincion-porinsecticidas-disminuyo-40-produccion-de-miel-en-jalisco-231422.html (Consultado el 4 de noviembre de 2019).

EntreDiversidades. Revista de Ciencias Sociales y Humanidades, vol. 8, núm. 1 (16), enero-junio 2021. Páginas: 64 - 91 ISSN-e: 2007-7610. https://doi.org/10.31644/ED.V8.N1.2021.A03 
Barsimantov, James y Navia, Jaime (2012). "Forest Cover Change and Land Tenure Change in Mexico's Avocado Region: Is Community Forestry Related to Reduced Deforestation for High Value Crops?” Applied Geography, 32 (2), pp. 844-853.

Bustamante, Tomás y Etienne, Jean (1999). "Los brebajes amargos del Tío Sam. Las trasnacionales estadounidenses de la agroindustria y el uso de pesticidas en México". Problemas del desarrollo, 30 (118), pp. 57-68.

Carrillo Armenta, Juan (2004). "Cuenca de Zapotlán. Deforestación y deterioro ambiental", Gaceta Universitaria de la Universidad de Guadalajara, II época, 4 (363) 11 de octubre de 2004, p. 18. También disponible en: http://www.gaceta.udg.mx/wp-content/ uploads/2020/02/363.pdf

Carrillo González, Digna Athziri (2019). Implicaciones territoriales en el paisaje por el cambio de uso de suelo en la microcuenca La Difunta, ladera nororiente del complejo Volcán-Nevado Colima (2000-2018). Tesis para obtener el grado de Maestría en Estudios Socioterritoriales, Universidad de Guadalajara.

Comisión Estatal del Agua del Estado de Jalisco (CEAS) (2015). Ficha técnica hidrológica municipal de Zapotlán el Grande. Guadalajara-México: Dirección de Publicaciones del Gobierno del Estado de Jalisco. Disponible en: https:/www.ceajalisco.gob.mx/doc/fichas hidrologicas/ region9/zapotlan\%20el\%20grande.pdf (Consultado el 11 de noviembre de 2019).

Comisión Nacional del Agua (CONAGUA) (2008). "La presa El Carrizo, en Jalisco, alcanza el $100 \%$ de su capacidad y empezó a desfogar excedentes”, Comunicado de prensa 186-08 , Ciudad de México, México: Comisión Nacional del Agua, Secretaría de Medio Ambiente y Recursos Naturales, pp 1-2. Disponible en: https://www.yumpu.com/es/document/

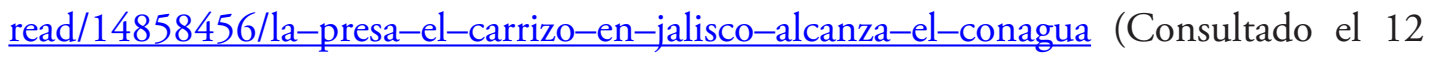
de noviembre de 2019).

Comisión Nacional del Agua (CONAGUA) (2019). Base de datos del Registro Público de Derechos de Agua (REPDA). Disponible en: https://app.conagua.gob.mx/consultarepda.aspx (Consultado el 12 de noviembre de 2019).

Cook, Roberta y Amon, Ricardo (1989). "Competition in the Fresh Vegetable Industry". Competitiveness at Home and Abroad, Report of a 1986-87 Study Group on Marketing California Specialty Crops: World Competition and Constraints. California, USA: University of California, Agricultural Issues Center, pp. 13-36.

De La Peña, Guillermo (1999). "Las regiones y la globalización: reflexiones desde la antropología mexicana”. Estudios del Hombre, núm. 10, pp. 37-57.

De Schutter, Olivier (2009). La agroindustria y el derecho a la alimentación. Informe del Relator Especial sobre el derecho a la alimentación, Organización de las Naciones Unidas, Consejo de Derechos Humanos, $13^{\circ}$ período de sesiones, 22 de diciembre. También disponible en: https://www.ohchr.org/Documents/Issues/Food/A.HRC.19.59.Add.5 SP.pdf

Del Castillo, Agustín (2019). "Huertas aguacateras, aumento dramático". Letra Fría, [en línea]. Disponible en: https://letrafria.com/huertas-aguacateras-aumento-dramatico/ (Consultado el 21 de abril de 2020).

EntreDiversidades. Revista de Ciencias Sociales y Humanidades, vol. 8, núm. 1 (16), enero-junio 2021. Páginas: 64 - 91 ISSN-e: 2007-7610. https://doi.org/10.31644/ED.V8.N1.2021.A03 
Diario Oficial de la Federación (DOF) (2013). Acuerdo por el que se actualiza la disponibilidad media anual de las aguas superficiales en las cuencas hidrológicas Laguna Villa Corona A, Laguna Villa Corona B, Laguna San Marcos-Zacoalco, Laguna de Sayula A, Laguna de Sayula B y Laguna de Zapotlán, mismas que forman parte de la Subregión Hidrológica Cuencas Cerradas de Sayula, de la Región Hidrológica número 12 Lerma-Santiago, 8 de julio. México: Ed. Talleres Gráficos de México. Disponible en: https://www.dof.gob.mx/ nota detalle.php? codigo $=5305865 \&$ fecha $=08 / 07 / 2013$ (Consultado el 23 de abril de 2020).

Estrada Ávalos, Juan, Víctor Gerardo Delgado Ramírez y Manuel Rodríguez Moreno (2018). Análisis espacial y temporal de la presencia de cañones antigranizo y su relación con la precipitación pluvial en los estados de San Luis Potosí, Jalisco y Michoacán. México: Instituto Nacional de Investigaciones Forestales, Agrícolas y Pecuarias de la Secretaría de Agricultura y Desarrollo Rural.

García, Omar (2015). "Productores piden reglamentar uso de cañones antigranizo". El Informador, [en línea]. Disponible en: https://www.informador.mx/Jalisco/Productorespiden-reglamentar-uso-de-canones-antigranizo-20150804-0110.html (Consultado el 15 de noviembre de 2019).

García de Alba García, Ricardo (2006). La actividad forestal en el sur de Jalisco y su influencia en la generación de la problemática ambiental en la Cuenca de Zapotlán. Tesis para obtener el grado de Maestría en Ciencias con Especialidad en Medio Ambiente y Desarrollo Integrado. México: Instituto Politécnico Nacional. Disponible en: https:/tesis.ipn.mx/ handle/123456789/1419 (Consultado el 14 de diciembre de 2019).

German Agency for Technical Cooperation (GTZ), Naciones Unidas (ONU), Comisión Económica para América Latina y el Caribe (CEPAL) (2005). Elementos conceptuales para la prevención y reducción de daños originados por amenazas socionaturales. Cuatro experiencias en América Latina y el Caribe. Cuadernos de la CEPAL No 91, Santiago de Chile: Comisión Económica para América Latina y el Caribe. Disponible en: https://www. cepal.org/es/publicaciones/27839-elementos-conceptuales-la-prevencion-reducciondanos-originados-amenazas (Consultado el 1 de marzo de 2019).

González, Humberto (1994). El Empresario Agricola en el jugoso negocio de las frutas y hortalizas en México. Tesis de Doctorado en Ciencias Agrícolas y del Medio Ambiente. Holanda: Universidad de Wageningen. También disponible en: https://edepot.wur.nl/132874

Gutiérrez, Rosario (2019). "Estas son las 12 mil hectáreas afectadas por los incendios en el sur de Jalisco". Estación Pacifico, [en línea]. Disponible en: https://estacionpacifico. com/2019/05/14/estas-son-las-12-mil-hectareas-afectadas-por-los-incendios-en-el_ sur-de-jalisco/ (Consultado el 1 de noviembre de 2019).

Hufschmidt, Gabi (2011). "A Comparative Analysis of Several Vulnerability Concepts". Natural Hazards, 58 (2), pp. 621-643. 
Instituto de Información Estadística y Geográfica de Jalisco (IIEG) (2017). Mapa de frontera forestal del Complejo Volcánico de Colima y cobertura de vegetación de la Sierra del Tigre. Guadalajara-México: Gobierno de Jalisco. Disponible en: https://iieg.gob.mx/contenido/ GeografiaMedioAmbiente/CambioUsoSuelo FronteraForestal.pdf (Consultado el 2 de febrero de 2019).

Instituto Mexicano del Seguro Social (IMSS) (2020). Trabajadores asegurados en el IMSS por municipio según relación laboral, al 31 de diciembre de 2019. [en línea]. Disponible en: www.imss.gob.mx (Consultado el 4 de mayo de 2020).

Instituto Nacional de Estadística, Geografía e Informática (INEGI) (2004). Censos Económicos 2004. México: INEGI. Disponible en: https:/www.inegi.org.mx/programas/ce/2004/ (Consultado el 14 de enero de 2020).

Instituto Nacional de Estadística y Geografía (INEGI) (2019). Censos Económicos 2019. [en línea]. Disponible en https://www.inegi.org.mx/programas/ce/2019/ (Consultado el 5 de octubre de 2020).

Macías, Alejandro (2008) "Costos ambientales en zonas de coyuntura agrícola. La horticultura en Sayula (México)”. Agroalimentaria, 13 (26), pp. 103-118.

Macías, Alejandro (2010). "Zonas hortofrutícolas emergentes en México ¿viabilidad de largo plazo o coyuntura de corto plazo? La producción de aguacate en el sur de Jalisco”, Estudios Sociales. Revista de Investigación Cientifica, 13 (36), julio-diciembre, pp. 203-235.

Macías, Alejandro (2011). Estrategias empresariales en la horticultura en México. Estudio de caso en Sayula, Jalisco. México: Plaza y Valdés, Universidad de Guadalajara, Organización de las Naciones Unidas para la Agricultura y la Alimentación.

Macías, Alejandro (2014). "Tú produce, del resto yo me encargo. Integración transnacional hortofrutícola en el Sur de Jalisco, México”, en: Humberto González; Margarita Calleja (eds.), Dinámica territorial agroalimentaria en tiempos de globalización. Zapopan-México: Universidad de Guadalajara, pp. 181-218.

Macías, Alejandro y Sevilla, Yolanda Lizeth (2015). "Caracterización de la producción de aguacate en el sur de Jalisco”, en: Alejandro Macías (coord.), La agroindustria del aguacate en el sur de Jalisco. Guadalajara-México: Universidad de Guadalajara, pp. 97-123.

Maisterrena, Javier y Mora, Isabel (2000). Oasis y espejismo. Proceso e impacto de la agroindustria del jitomate en el valle de Arista, S. L. P. San Luís Potosí-México: El Colegio de San Luis, Gobierno del Estado de San Luís Potosí.

Martin-Culma, Yolieth Nazly y Arenas-Suárez, Nelson Enrique (2018). "Daño colateral en abejas por la exposición a pesticidas de uso agrícola”, Entramado, 14 (1), pp. 232-240.

McMichael, Philip (1994). The Global Restructuring of Agro-Food System. Ithaca, United States: Cornell University Press.

McMichael, Philip (2002). "Global Development and the Corporate Food Regime". Research in Rural Sociology and Development, [en línea] 11, pp. 265-299. DOI: https://doi. org/10.1016/S1057-1922(05)11010-5 (Consultado el 8 de junio de 2010).

EntreDiversidades. Revista de Ciencias Sociales y Humanidades, vol. 8, núm. 1 (16), enero-junio 2021. Páginas: 64 - 91 ISSN-e: 2007-7610. https://doi.org/10.31644/ED.V8.N1.2021.A03 
Méndez, Ernesto (2011). "Premian a ecocida; será delegado de la Semarnat en Nayarit”. Excelsior, [en línea] Disponible en: https://www.excelsior.com.mx/2011/05/13/nacional/736462 (Consultado el 31 de noviembre de 2019).

Michel Parra, J. Guadalupe, et al. (2005). Ficha Informativa de los Humedales de Ramsar (FIR). Sitio Ramsar Laguna de Zapotlán. México: Convención sobre Humedales. Disponible en: https://semadet.jalisco.gob.mx/sites/semadet.jalisco.gob.mx/files/ficha informativa.pdf (Consultado el 24 de octubre de 2019).

Michel Parra, J. Guadalupe y Guzmán Arroyo, Manuel (2012). “'Laguna de Zapotlán’, sitio Ramsar núm. 1466, humedal de importancia internacional”. En: Salvador Peniche Camps, et al. (Coords.), III Seminario Internacional sobre la Cuenca del Río Santiago. Retos y perspectivas de las áreas naturales protegidas. Guadalajara-México: Universidad de Guadalajara, pp. 79-101.

Michua-Cedillo, Jeny, et al. (2017). "Epidemiología del patosistema Armillaria spp. - persea americana mill. en tres municipios de la franja aguacatera de Michoacán”, Memorias del $V$ Congreso Latinoamericano del Aguacate, septiembre 2017, Ciudad Guzmán, Jalisco, México. También disponible en: http://www.avocadosource.com/journals/memorias vcla/2017/memorias vcla 2017 pg 154.pdf

Moreno, José Luis (2000). "Conocimiento y estudios sobre el agua subterránea en la Costa de Hermosillo". Región y Sociedad, 13(7), pp. 75-110. También disponible en: https://doi. org/10.22198/rys.2000.20.a745

Organización de las Naciones Unidad para la Agricultura y la alimentación (FAO-Faostat) (2020). Estadisticas de producción agricola. Disponible en: http://faostat.fao.org/ (Consultado el 21 de abril de 2020).

Pérez, Isabel (2018). “¿Control de nubes? El mito de los cañones antigranizo”. Ciencia UNAM, [en línea]. Disponible en: http://ciencia.unam.mx/leer/707/-control-de-nubes-el_ mito-de-los-canones-antigranizo- (Consultado el 15 de noviembre de 2019).

Rodríguez Pinto, Cristian (2018). "Ocurren en el sur de Jalisco 56\% de los incendios forestales intencionales”. El Suspicaz, [en línea]. Disponible en: https://elsuspicaz.com/ocurrenen-el-sur-de-jalisco-56-de-los-incendios-forestales-intencionales/ (Consultado el 1 de noviembre de 2019).

Rodríguez Pinto, Cristian (2019). "Atribuyen incendios en Jalisco a la intención de sembrar aguacate”. El Suspicaz, [en línea]. Disponible en: https://elsuspicaz.com/atribuyenincendios-en-jalisco-a-la-intencion-de-sembrar-aguacatel (Consultado el 31 de octubre de 2019).

Rodríguez Soto, Eduardo (2011). "Investigan a delegado de Semarnat en Jalisco por tala de árboles". Animal Político, [en línea]. Disponible en: https://www.animalpolitico. com/2011/01/investigan-a-delegado-de-semarnat-en-jalisco-por-tala-de-arboles/ (Consultado el 31 de octubre de 2019).

Salvador y Maldonado (2012). “Aguacateros “aniquilaron” a las abejas en valle de Zapotlán”. El Informador, [en línea]. Disponible en: https://www.informador.mx/Jalisco/Aguacaterosaniquilaron-a-las-abejas-en-valle-de-Zapotlan-20120206-0108.html (Consultado el 1 de noviembre de 2019).

EntreDiversidades. Revista de Ciencias Sociales y Humanidades, vol. 8, núm. 1 (16), enero-junio 2021. Páginas: 64 - 91 ISSN-e: 2007-7610. https://doi.org/10.31644/ED.V8.N1.2021.A03 
Sánchez Bacilio, Alfredo (1992). El cultivo depapa en el municipio de Tapalpa, Jalisco. Tesis para obtener el grado de Licenciatura en Ingeniero Agrónomo Fitotecnista, Universidad de Guadalajara. Disponible en: http://repositorio.cucba.udg.mx:8080/xmlui/handle/123456789/505 (Consultado el 8 de septiembre de 2019).

Santana Aispuro, Enrique (2014). Multifuncionalidad y transformaciones en el territorio de la microcuenca de Tapalpa, Jalisco. Tesis para obtener el grado de Maestría en Ciencias en Manejo de Recursos Naturales, Universidad de Guadalajara. Disponible en: http://www. cucsur.udg.mx/sites/default/files/santana aispuro enrique 2014.pdf (Consultado el 23 de mayo de 2020).

Secretaría de Agricultura y Desarrollo Rural. Servicio de Información Agrícola y Pecuaria (SADER-SIAP) (2020). Anuarios de producción agrícola en México. México: Gobierno de México. Disponible en: https://www.gob.mx/siap/acciones-y-programas/produccionagricola-33119 (Consultado el 26 de marzo de 2020).

Secretaría de Medio Ambiente y Recursos Naturales, Dirección General de Impacto y Riesgo Ambienta (SEMARNAT-DGIRA) (2007). Oficio S.G.P.A-DGIRA-DG-3191/07, dirigido a la Secretaría de Desarrollo Rural del Gobierno del Estados de Jalisco, en el que se da a conocer el análisis y evaluación del proyecto "Presa Vista Hermosa, Jalisco", 19 de diciembre de 2007. Disponible en: http://sinat.semarnat.gob.mx/dgiraDocs/documentos/ jal/resolutivos/2007/14JA2007HD006.pdf (Consultado el 25 de marzo de 2020).

Sefó, Jose Luis (2005). La calidad es nuestra, la intoxicación... ;de usted!. Zamora-México: El Colegio de Michoacán.

Sepúlveda Velázquez, Laura (2016). "Buscan frenar muerte de abejas”. La Gaceta de la Universidad de Guadalajara, [en línea]. Disponible en: http://www.gaceta.udg.mx/Buscan-frenarmuerte-de-abejas/ (Consultado el 12 de noviembre de 2019).

Servicio Geológico Mexicano (2007). Causas, características e impactos. Museo Virtual de Geología del SGM. [en línea]. Disponible en: https://www.sgm.gob.mx/Web/MuseoVirtual/ Riesgos-geologicos/Causas-caracteristicas-e-impactos.html (Consultado el 13 de febrero de 2020).

Smit, Barry y Pilifosova, Olga (2003). "From Adaptation to Adaptive Capacity and Vulnerability Reduction”, en Joel B. Smith, Richard J. T. Klein y Saleemul Huq (Eds.), Climate Change, Adaptive Capacity and Development. London-UK: Imperial College Press, pp. 9-28.

Stanford, Louis (1994). "Transitions to Free Trade: Local Impacts of Changes in Mexican Agrarian Policy”. Human Organization, 53 (2), pp. 99-109.

Téliz, Daniel (2008). "Manejo integrado del aguacate". Conferencia impartida en el Primer Congreso Nacional del Sistema Producto Aguacate. Uruapan, Michoacán, México, 5 de diciembre de 2008.

Téliz, Daniel y Mora, Antonio (2008). El aguacate y su manejo integrado. México; Madrid: Mundi Prensa.

Velazco, Jorge (2016). "Mueren envenenadas abejas en sur de Jalisco". Milenio, [en línea]. Disponible en: https://www.milenio.com/negocios/mueren-envenenadas-abejas-en-

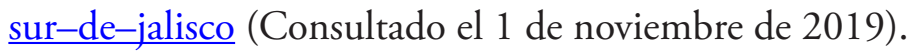

EntreDiversidades. Revista de Ciencias Sociales y Humanidades, vol. 8, núm. 1 (16), enero-junio 2021. Páginas: 64 - 91 ISSN-e: 2007-7610. https://doi.org/10.31644/ED.V8.N1.2021.A03 
Villalvazo Chávez, Héctor (1995). "Se produjeron 21 mil toneladas de jitomate de calidad". Tzaulan, pp. 1-10.

Zamudio Zavala, Pablo Enrique, Maximiano Bautista Andalón e Iván Gómez Mora (2016). “Atlas Municipal de Peligros y Riesgos Naturales del municipio de Zapotlán El Grande (Cd. Guzmán), Jalisco". XXVIII Reunión Nacional de Ingeniería Geotécnica. Mérida, Yucatán, México: Sociedad Mexicana de Ingeniería Geotécnica, A.C., pp. 1-10. Disponible en: https://www.researchgate.net/publication/327779075 Atlas Municipal de Peligros y Riesgos Naturales del municipio de Zapotlan El Grande Cd Guzman Jalisco (Consultado el 15 de octubre de 2019). 